\title{
Mental State Attribution
}

\author{
by
}

Andrea J. Purton

Submitted in partial fulfillment of the requirements for the degree of Master of Arts

Dalhousie University

Halifax, Nova Scotia

December 1998

C) Copyright by Andrea J. Purton 
National Library

of Canada

Acquisitions and Bibliographic Services

395 Wellington Street Ottawa ON KIA ON4 Cansda
Bibliothèque nationale du Canada

Acquisitions et services bibliographiques

395, rue Wellington

Ottawa ON K1A ONA

Canada
The author has granted a nonexclusive licence allowing the National Library of Canada to reproduce, loan, distribute or sell copies of this thesis in microform, paper or electronic formats.
L'auteur a accordé une licence non exclusive permettant à la Bibliothèque nationale du Canada de reproduire, prêter, distribuer ou vendre des copies de cette thèse sous la forme de microfiche/film, de reproduction sur papier ou sur format électronique.

L'auteur conserve la propriété du droit d'auteur qui protège cette thèse. $\mathrm{Ni}$ la thèse ni des extraits substantiels de celle-ci ne doivent être imprimés ou autrement reproduits sans son autorisation. 
Abstract 2 Page

Introduction - Ch. 1:How Folk Psychology Works: ST vs. TT

Section I: Attribution of Mental States to Other -

theory theory-_-2

simulation theory 6

objections to $S T+10$

Section 2: Attribution of Mental States to the Self

ST account of self knowledge 16

Robert Gordon - 17

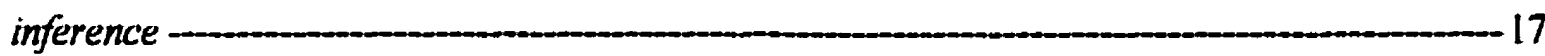

introspection-10 18

TT account of self knowledge _-___-20

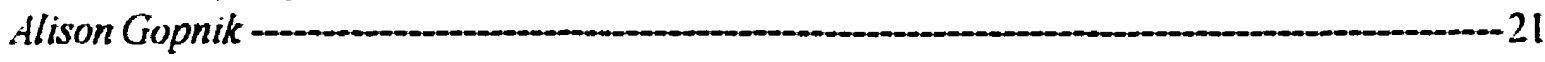

the illusion of expertise

Ch. 2: Empirical Evidence for ST and TT -27

false belief task _-_ 28

$T T$ explanation of false belief -

ST explanation of false belief ___

2nd order false belief - 32

other tasks -

cutism - 40

evidence for error in self attribution

Ch. 3: The Role of Functionalism in the Debate

$S T$ and TT in functionalist terms-__ 45

Alvin Goldman -

mistaken attribution - 59

absent or contradictory intrinsic qualities

automatic knowledge-_- 61 
Conclusion $-65$

Bibliography$-66$ 


\section{Abstract}

There is a debate in philosophy of mind as to whether we understand the mental states of others and ourselves by constructing a theory about mental states (the "theory theory") or by a non-theoretical replication of the mental state of others (the "simulation theory"). I divide the debate into two sections, one attributing mental states to others, the other attributing mental states to the self. I also give a sample of empirical evidence from developmental psychology that is relevant to the debate.

The central debate can be reworked in functionalist terms. I find that the theory theory is a functionalist theory, while the simulation theory is not. Instead of a functionalist definition of mental states, the simulation theory relies on a direct phenomenological recognition of own mental states. I argue that lack of a functionalist understanding of own mental states leads to insurmountable problems for the simulation theory in certain areas of own state attribution. In particular, I find that instances of discrepancy between state attribution and behaviour, and instances of state attribution without the corresponding intrinsic qualities are not explainable in non-functionalist terms. I find, therefore, that simulation theory is wrong about mental state attribution. 


\section{Acknowledgements}

I would like to thank my Supervisor, Dr. Robert Martin, for his guidance and patience during a busy time of year, Dr. Melinda Hogan for inspirational discussion and advice throughout this project, and Dr. Duncan Macintosh for his support and final readings.

I would also like to thank my parents, Sandra and Chris Purton, for their boundless support. 


\section{INTRODUCTION - CHAPTER ONE}

\section{How Folk Psychology Works: ST us TT}

Folk Psychology (FP) is a largely successful theory of mind that at the very least consists in a) a number of mental concepts, and b) practices in which these concepts are used or applied. Mental concepts refer to contentful psychological states, which means that, for example, suspicion about someone, love for something, pain in a particular area of the body, recognition of a place, fear of the unknown, desire for an article, belief about a state of affairs, intentions to do an action, etc., are mentioned to explain, predict, and understand behaviour, internal states, contextual circumstances and the relationships between these. Thus, any action/behaviour/attitude can be explained (understood, etc.) as propositional attitudes: for example, the reason that John was at the cafe at 5:00 pm was because he believed that Mary would be there and he wanted to see Mary (or, in proper but awkward propositional attitude form: he desired that he see Mary). His belief that Mary was there was based on a prediction involving further propostional attitudes about Mary (she likes going to this cafe, she has a habit of going to the cafe on Tuesdays, etc.)

So far I have outlined a very basic description of FP as philosophers see it. However, psychologists are also interested in FP, and have a much broader understading of its content (this is especially true of social psychology). In social psychology, FP can include explanations of behaviours in terms of personality traits or dispositions. FP can be expressed in proverbs and fables, can include general basic beliefs like the belief in other minds; and, though it is a shared body of knowlege, it can vary among cultures, religions, genders, etc. 


\section{SECTION 1: ATTRIBUTION OF MENTAL STATES TO OTHERS}

\section{Theory Theory (TT)}

It has been suggested that folk psychology (FP) actually is a theory in the formal sense (by Paul Churchland for example), in which we arrive at explanation through deduction, drawing on a body of knowledge that contains such common-sense general laws as:

-a person who suffers severe bodily damage will feel pain

-a person who feels overall warmth will tend to relax

-if $x$ fears that $P$, then $x$ desires that not $P$

On this account, folk psychology not only has explanatory value, but also has a definite structure in which propositional attitudes are used in a system with logical laws, much like the logical system of mathematics or physics. Folk Psychology is a theory that includes a series of sentences like the examples just given. Those sentences, when combined with other sentences, can be followed through to a conclusion. In folk psychology, these laws support counterfactuals: e.g., if someone has not had a drink in two days, that person would be thirsty and would be caused by that thirst to try very hard to find themseives a drink.

This account of how folk psychology works is called the "Theory" theory (TT); it is the theory that folk psychology is a theory. I have just described the theory theory in the strict sense. However, this term is also used in a less restrictive way. Depending on how "theory" is defined, "theory theory" can refer to a number of different ways in which folk psychology works. The exact definition of the term "theory" is under debate in philosophy. However, there are a number of defining characteristics which, taken in some combination, are generally taken to constitute a theory. None of these characteristics will stand on its own as a definition of theory, and some of these characteristics of theories are more widely accepted by philosophers than others.

1. Theories are used for explanation and prediction. Astronomical calculations are 
used to predict the position of stars and planets. In FP calculation, I basea prediction on mental states that I attribute to you: I expect to see you in Cousin's Diner tomorrow morning since we agreed to have breakfast there, and I think you are a person of your word, and that you will remember our agreement, and that you believe that I will be there too.

2. Theories deal with counterfactual situations. For example, "If the sugar were put in to a glass of water it would dissolve," or, "If I had been at the party, she would have had a fit."

3. Theories postulate unobservable entities or concepts to explain observable behaviours. So, just as genes were postulated to explain observable physiological traits, beliefs, desires, and emotions are postulated to explain outward behaviour. This last characteristic can also be understood to be about "abstractness": theories do not just restate or describe data; they explain or interpret data.

4. Theories include an implicit definition of concepts. A theory will give an indication of how to understand concepts like hope, intend, try, want. For example, the concept of belief is how that belief is connected to behavioural output and environmental inputs.

5. Finally, theories are defeasable, and so are dynamic. Counterevidence can cause a theory to be changed or replaced altogether.

TTists have differing ideas about what a theory of mind would look like. There are a number of ways the mind could store and transmit theoretical information. The examples from Churchland given above model FP theory on scientific theory. However, FP theory structure could also be modeled on theoretical linguistics, or it could be simply understood to be any kind of body of knowledge. For example, broadly construed, TT can refer to any kind of stored information at all, so that non-sentential models (like the connectionist model) of mental states also fall under the heading of TT. 
Philosophers who take FP theory as scientific theory (e.g. Gopnik, Wellman) emphasize characteristics found in FP theory such as deductive-nomological explanations (as in the examples from Churchland), postulation of an unobservable inner life based on observable behaviour, and understanding of concepts by virtue of their location in a larger theory and by their interconnection with other concepts (intentional states like belief do not stand on their own - they only make sense within the larger theory of mind). Development of a FP theory by children has been compared to the kind of theory building that is done consciously by scientists as they move from a rough to a more sophisticated theory: As Gopnik and Wellman put it:

Recent evidence suggests that during the period from three to four many children are in a state of transition between the two theories, similar, say, to the fifty years between the publication of De Revolutionibus and Kepler's discovery of elliptical orbits. (p. 242)

The problem with treating FP theory as a scientific theory is that they are disanalogous on several points. FP theory just is not all that much like theories in chemistry and physics. It is made up and used by common folk (even by children), it is not subjected to empirical tests, it is not taught or learned in at all the same way as we learn scientific theories, and it is not written down anywhere to be expanded upon by future theorists.

The disanalogies between science and folk psychology have led many philosophers to instead model FP theory on theoretical linguistics. For example, Stich and Nichols (1992 p.36) compare the TT to the "dominant explanatory strategy":

...the dominant explanatory strategy proceeds by positing an internally represented "knowledge structure" - typically a body of rules or principles or propositions - which serves to guide the execution of the capacity to be explained. These rules or principles or propositions are often described as the agent's "theory" of the domain in question. In some cases, the theory may be partly accessible to consciousness; the agent can tell us some of the rules or principles he is using. More often, however, the agent has no conscious access to the knowledge guiding his behavior. 
In this model of the TT the FP theory is implicit, much like the capacity to understand, produce, and recognize the grammaticality of an infinite number of sentences. Speakers can not necessarily explain their ability in terms of the grammar of the language (unless they have subsequently learned linguistics or read Chomsky) - they just know if a sentence is right by the fact that it sounds right. Language speakers possess an implicit theory of grammar and sentence building. Similarly, we possess an implicit theory of folk psychology. Neither of these abilities is taught; they are acquired at an incredible speed at a young age, and seem to be independent of other intellectual capacities.

In the theoretical linguistic model of a theory of mind, the term "theory" still refers to the view of mental states as abstract postulated entities which interconnect in a causal lawlike fashion so that we may understand, predict, etc. the actions of others. However, the theory of mind is not consciously posited. Instead, it is a theory of mind module, or modules - innate mechanisms in the mind specifically devoted to theory of mind tasks. This module develops by maturation, and is triggered by experience, rather than consciously developed by experience in the manner of "child as scientist". Modularity theorists understand theory of mind as a representational ability which is possessed by all humans.

A final model of the theory theory of mind is to take theory to refer to some internally represented body of knowledge, however that knowledge may be represented. A theory of FP may be structured as a list of rules or propositions, or it may be structured non-sententially, like the connectionist model. It could be practical knowledge about the domain of psychology, just as there is a body of knowledge about cooking or rules of etiquette. The theoretical structure which produces this body of knowledge may be accessible to the subject or it may not. This construal of theory has been criticized as being so broad that it becomes trivial because practically everything could be understood to be a theory in this sense. However, Stich and Nichols (for example) like to define theory so that TT and ST are mutually exclusive. Any evidence for one will count as 
evidence against the other. If theory is too narrowly defined, it becomes ambiguous whether empirical evidence against the TT could not be accounted for with a different version of the TT.

Finally, there are two components to the TT. Along with a body of knowledge, there is some kind of information-processing mechanism that makes use of that knowledge. The fact that there are two components to the TT makes for disagreement as to whether maturation is a matter of theory acquisition or is a matter of development of theory-processing mechanisms.

\section{Simulation Theory (ST)}

An alternative to TT is the Simulation Theory (ST). Simulation theory was first presented as a worked-out systematic theory in three papers: Jane Heal's "Replication and Functionalism" (1986), Robert Gordon's "Folk Psychology as Simulation" (1986), and Alvin Goldman's "Interpretation Psychologized" (1989). There were already differences of opinion over the construal and uses of ST in these initial defenses, but we can disregard these differences in a basic understanding of ST.

On the ST account, folk psychology, or "mind reading" is not a matter of processing general laws about human behaviour. Instead it is a capability that we have to simulate the experience of another enough to be able to predict or explain their actions. Very simply, we pretend to be them, then decide what we will do next. This capability uses the program already in place in our minds that we use to make decisions and direct our own actions. The decision-making process happens something like this: Beliefs and desires are fed into a practical reasoning system (a decision-making system). This system comes up with a decision based on the original inputs, and transfers this decision to the action-carrying-out system, or alternatively, runs it back around to generate further beliefs and desires. The action system then controls the behaviour of the person, so that 
output is the carrying out of decisions made in the practical reasoning system. That is the process for initiating our own behaviour.

A simulation uses the same process, except that it is run "off-line", so that all parts of the program are working except the final part -- the activation of behaviour. When, in our own case, the output of the program would be a particular action, in a simulation, the output is a prediction (or explanation or description) of someone else's behaviour. So, for example, if you tell me you have a craving for chocolate, and I see you fishing for change in your pocket, and I know the store across the street is open, I do not predict your next move by flipping through a number of laws about human behaviour, plugging in the variables (If person $P$ desires chocolate $C$, and buying chocolate at the store will bring it about that that person will acquire chocolate, etc....). Instead I run through a decision-making process in which I am a person who craves chocolate, has money, and knows the store is open, and I make up my mind what I will do next. This decision is made the same way it would be if all those things were actually the case, except that the action section of the process is "turned off", and the mental organs are operating "off-line". When I am done, I attribute the decision to you. I have simulated being in your position and have come up with a prediction for your immediate action. As Davies puts it (Davies, 1993 p. 104), "Instead of being theorizers, we are simulators".

There are two main components to a simulation. One is the "reading off" of the decision after it has been run through your own system, and the other is the inference or analogy made to the target subject. The introspection-inference view of simulation is accepted by all simulation theorists except Robert Gordon later on in his philosophical career. His alternative to introspection is described in the next section (ST account of self knowledge).

On the ST account, predicting the behaviour of others is an extension of our ability to predict our own behaviour. Predicting our own behaviour is done by simulation as well. The trick to predicting our own behaviour is to make up our minds, then simply 
announce what it is we have made up our minds to do. So, for example, I will have a highly successful prediction rate if $I$ announce that:

I shall now pour some coffee

I shall now pick up the coffee cup.

I shall now drink the coffee.

This self-prediction also works in counterfactual situations. So if I want to predict what I would do if I heard an intruder in the house, right now, as I write, I would simply imagine a possible situation in which every detail except one is the same as it is now. That one detail is the sound of an intruder. Once I have imagined this, I then "see" what I would do. In this case, my simulation of that possible situation gives me the prediction that I would reach for the phone and dial 911. (Both these examples are from Gordon, 1986.)

Extending this kind of prediction to the third person case, we run a similar simulation, taking into account the relevant differences between them and us, and "see" what we would do. It is important to note that the third person simulation is not just a matter of imagining ourselves in our target person's place. It is us, as far as is possible given the information we have, being like them. The simulation is running through our mind, but we are taking all the information we have about our target person in order to make our situation as much as possible like theirs. For example, if I am driving and I see a child chasing a ball that is about to roll onto the street, I take into account the fact that I (as child) am not all that familiar with the idea of traffic, that I have a great interest in the ball, that I have not yet been taught to look both ways before crossing the street, etc. even though I (as me) am excessively careful about crossing the street, and am aware of the dangers of cars. This allows me to predict that the child will run out onto the street, and I stop my car accordingly. If I had been simulating by placing myself in the child's position, I would feel no need to stop my car, since it would be unlikely that I would chase a ball out into traffic. 
Gordon allows (1995) that we don't always take into account as many of the relevant differences as we should in order to understand someone else's situation (hence the expression: "try putting yourself in her place"). Sometimes we do just imagine ourselves in the target person's place, and make our prediction or explanation accordingly. So if I say of a squeegee-kid that he should get a proper job and that he is lazy, and that furthermore, I had a regular job in a company when I was his age, I am not taking relevant differences into account in my explanation of his behaviour, such as differences in education, perceived self-worth, family support, ability, background, etc. Gordon calls this total projection, because we are projecting ourselves and all our qualities into whatever situation we are examining. This way of understanding others with the least amount of effort or least change of input is our default position. Sometimes it is all that is necessary to get a prediction of another's behaviour, but it can also lead to error. Gordon still thinks, though, that this total projection of ourselves counts as simulation, even if it is not a very good simulation.

So far, most of the discussion and examples of simulation have been related to prediction. Simulation is also used to explain behaviour, to describe mental states, and even on some accounts (Gordon, 1986) to give a meaning to intentional states such as belief and desire. To explain behaviour, we look for the beliefs and desires that would be the most likely to give the behavioural output witnessed. I explain the fact that my friend did not say hello to me by saying, "he didn't see me". There is an endless number of possible intentional states to explain any situation (for example I could say "my friend was abducted by aliens who put a robot body in his place and the robot was not programmed to recognize me as a friend"), but we use the "principle of least pretending" (Gordon 1986) to find the most plausible explanation. Goldman writes that we attribute beliefs that are "most natural to us" (Goldman 1989) We run those most likely beliefs and desires through our prediction program, and if we come up with the expected behavioural output, then we take those beliefs and desires to be the correct explanation for behaviour. 
The views of simulation theorists range in strength. According to the strong claim, simulation is sufficient to acquire intentional states. In this sort of claim, the simulation itself constitutes an understanding of cognitive concepts or is itself the content of intentional states. So terms such as "believes that", "desires that" are fully explained by a simulation. No extra theorizing is necessary to aquire knowledge of intentional states. Gordon's example of this kind of strong claim is this: (Gordon 1986 p.68)

I. Let's do a Smith simulation. Ready?: Dewey won the election.

2. Smith believes that Dewey won the election.

Those two sentences are equivalent. On Gordon's account, to simulate someone's experience, it is not necessary to think "I believe that $\mathrm{P}$ " while simulating. Instead we simply think "P" while imaginatively identifying with someone else.

. A weaker claim is that simulation is necessary, but not sufficient to acquire intentional states. In this sort of claim, simulation only helps to acquire intentional concepts along with some theoretical method. Still weaker is the claim that we need to already understand intentional concepts in order to be able to simulate at all, and simulation is useful only to establish connections between those states. Alvin Goldman is a proponent of this weak sort of claim.

\section{Objections to ST}

A host of problems associated with the simulation view will have occurred to the reader. I will give an overview of the main objections to ST, along with some examples of responses to these objections.

Many of the perceived problems with ST have to do with the fact that ST, in one way or another, can't shake the TT. ST either needs theory at some point in its process, or is in fact consistent with the theoretical view. There are a number of places that theory enters in to ST:

i) Daniel Dennett writes of a simulation type view: 
How can it work without being a kind of theorizing in the end? For the the state I put myself in is not belief but make believe belief. If I make believe I am a suspension bridge and wonder what I will do when the wind blows, what "comes to me" in my make believe state depends on how sophisticated my knowledge is of the physics and engineering of suspension bridges. Why should my making believe I have your beliefs be any different? In both cases knowledge of the imitated object is needed to drive the make believe "simulation" and the knowledge must be organized in something rather like a theory. (Dennett, 1982, p. 79)

In this objection, determining the most likely behaviour for the target person involves knowledge of laws about the states that are imagined. The simulation is only possible because we have recourse to a theory that allows us to predict outputs based on inputs. Transitions in thought (I perceive $\mathrm{x}$, therefore I think $\mathrm{y}$ ) happen because we use the underlying theory which tells us which thoughts lead to other thoughts and which combination of thoughts lead to which kinds of actions. The practical reasoning part of our program needs a theory in order to work.

Alvin Goldman (1989) answers this objection by maintaining that not all mental simulations must be theory-driven (though some are). Simulations can instead be process-driven. This is conceivable because the two systems (i.e., the cognitive process of the simulator and the cognitive process of the target person) are the same in relevant ways, and the cognitive processes have relevantly similar inputs; so they will have similar final states because they have similar initial states (the simulator "pretends" the initial state of the target person). The simulator does not need any theoretical information about part of the target person's cognitive system, because all the simulator is doing is running a program that is equivalent to the target's program. No special knowledge of how that program works is necessary; all that is necessary are the correct inputs, so long as the two programs work the same way.

Jane Heal (1986) writes that Dennett's sort of objection forgets that our psychology is more like the psychology of other people than it is like the state of being a suspension bridge. Of course, differences in persons make for differences in reactions and 
actions in particular situations. However, our systems are sufficiently like the systems of others to be able to equate what Dennett calls "make believe belief" with imagining what we ourselves would do in a similar situation. When we make a decision for ourselves, we imagine the possible outcomes and relevant states of affairs in order to come up with some basis for our own actions. That is the same process we use on other people. So a theory in the sense meant by Dennett is not a necessary part of ST. What is necessary is the ability to distinguish between our own beliefs and imagined other people's beliefs and the capability of attributing a belief to another person.

ii) A second objection to $\mathrm{ST}$ is that theory is needed to determine which differences are relevant between the simulator and the target person. We have to decide somehow which beliefs and desires are appropriate in order to put ourselves in the same state as the other, but in order to do that, we need some kind of theory to tell us how and in which way psychological states are related to each other, and how the psychology of the target person works.

Heal responds to this objection by saying that it "misdescribes the direction of gaze of the replicator" (Heal, 1986). The simulator is using practical information from the surroundings of the target person, attempting to take the world in from that person's eyes; and so she is using information from the world, not from the psychology of the target person. Having a picture of the world surrounding the target person means being in that position oneself. Gordon (1995) illustrates this point with an example in which you are walking with a friend in the forest and suddenly see him turn and run. You can not explain his behaviour by examining the laws governing the interaction of his mental states. His behaviour is only understandable when you stand where he was standing and see a bear. That information from the outside world gives your simulation machine enough inputs to work with in order to establish an explanation. 
iii) A third objection is the Cognitive Penetrability argument (developed especially by Stitch and Nichols, 1992 and 1995). Stich and Nichols argue that predictions of behaviour based on simulations are not "cognitively penetrable" - that is, it is not necessary to know how minds work in order for the simulation to yield the correct prediction or explanation. Predictions based on theory, on the other hand, make use of any information about the processes governing the relations between psychological states, inputs from the environment, other psychological states, and behavioural output. Since off-line simulation is not affected by further information on the processes governing the workings of the mind, its predictions need nothing more than the appropriate inputs to predict accurately.

The problem arises with false predictions. On the TT account, a false prediction is a result of some incompleteness or some error in the theory: some misinformation about psychological states has been applied. ST has no such explanation for inaccurate predictions of behaviour since all a simulation needs to run properly are the relevant inputs. In cases where the appropriate inputs are available, and a false prediction is made, the simulator is not allowed to explain by pointing to the false opinions held by the simulator regarding the target person because that would demonstrate that the process used to make the prediction is cognitively penetrable. It seems that a little piece of theory is needed to explain what went wrong in a false prediction.

Stich and Nichols cite some empirical evidence for this claim (Stich and Nichols, 1992). They claim that there are numerous examples in cognitive social psychology in which persons are inclined to make false predictions even about themselves as a result of ignorance of the workings of the psychology of themselves or others. In one such experiment (from Nisbett and Ross), persons were asked to choose a higher quality product from (unbeknownst to them) two identical products. It was found that the position of the product had a significant effect on the choice - a high number of people choose the product on the right as being of higher quality. Now this should be foreseeable 
if we make behaviour predictions with ST - all the information is available, and we should have no problem "pretending" the scene. Yet, in prediction and in discussion after the choice was made, none of the subjects thought that position of product would or did affect their decision. Stich and Nichols think that these kinds of experiment demonstrate that incompleteness of a theory of our own behaviour leads to error in prediction and explanation.

This objection is tackled at length by Jane Heal (Heal, 1996). Generally it can be claimed that the simulation theorist never has all the relevant inputs, and so can not generate an accurate prediction. For example, those told about the experiment only hear about it, and are not presented with the products visually, that is, not in the same way those in the experiment received inputs. Also, the predictors are given additional information that they would need to disregard in their simulation (e.g., that the products are identical). Also, the simulation theorist can agree that at some times, some nonrational, purely mechanical knowledge is needed to make a prediction. For example predicting what someone will do once they have swallowed a drug is impossible unless we have some information about the effects of that drug or unless we have swallowed the drug ourselves. But this does not defeat the ST or blur the line between ST and TT

iv) Paul Churchland (Churchland 1989) thinks that ST is in fact consistent with TT in the sense that observing our own behaviours and experiences in response to various environmental inputs adds to a general theory of mind. However, if the ST holds that we understand others by extrapolating from our own experience so that a theoretical framework is not necessary, then ST is wrong. He finds that simulation is neither necessary nor sufficient for understanding, predicting, explaining, etc. the experience of others.

He thinks that simulation is not necessary because there are many situations in which we can predict or understand the behaviour of another, even though we have never 
experienced what they are experiencing. Thus someone who is blind or deaf knows and can count on the fact that others are not similarly afflicted, and that their actions will be different for that reason. Churchland points out that people who have never felt profound grief, or love, or rejection are nevertheless able to predict, explain, and even understand the behaviour of others feeling that emotion. Our own experience with emotions, beliefs, desires, hopes, intentions, attentions, etc. is actually very small, whereas our understanding of behaviours covers a large range or explanations, including explanations in terms of mental states we ourselves have never been in.

Churchland also thinks that simulation is not sufficient for a folk psychological understanding of others. For even if the output of a simulation allowed us to predict what someone would do in such and such a situation, we are still lacking any explanatory understanding of that person's actions. We still do not know why someone does what they do because we have no general connections between actions and reasons for actions. Having a model or program of some else's situation does not constitute an understanding of that situation. Churchland likens this to having a tiny model of the giobe, with everything working the way it does in the real globe. We would have a little model, but we still would not understand how either of those systems worked. In order to understand how the target system works, we need a theory of the general patterns that govern both the target subject and the original subject. Armed with such a theory, we could understand why it is that both systems behave in the same way.

\section{SECTION II: ATTRIBUTION OF MENTAL STATES TO THE SELF}

In this section, I narrow the focus of discussion in order to describe how simulation theorists and theory theorists explain self-knowledge. By self knowledge I mean knowledge of the content of our own mental states (e.g. knowing that I desire an ice-cream cone, or that I am in pain, or that I am angry, that I intend to go running, that I 
hope, realize, forget, etc.), and knowledge of the outcome of having those mental states (i.e. predicting, explaining and describing my own actions in terms of those mental states). Self knowledge also means awareness of the source of my mental states, memory of past mental states and past actions, knowledge of my own personality traits, awareness of my own plans, awareness of my own emotions, awareness of the direction of my attention, awareness of my own abilities, etc. In short, self knowledge is the directing of folk psychology towards the self.

ST and TT differ considerably in their explanations of self knowledge. Self knowledge raises specific problems for each account, and much of the literature on self knowledge is directed towards explaining away the problematic implications that arise.

\section{ST Account of Self Knowledge}

In simulation theory, self knowledge is generally assumed. After all the business of feeding inputs into our own system and running them through along with any extra information we have about the situation and the target person, all we have to do in order to make a prediction or explanation of behaviour is to "read off" our own output results. We know what we feel or what we would do just by "looking". Introspective accounts are traditionally problematic, so most ST accounts include a section in which they explain that ST introspection is not the same kind of introspection that Descartes was talking about, and that omniscience and infallibility is not necessarily a part of the ST account. There are few simulation theorists who focus on the introspection aspect of ST much more than that. Two simulation theorists who do say more about introspection are Alvin Goldman and Robert Gordon. Alvin Goldman's article. "The psychology of folk psychology" (1993) defends an introspectionist account of self knowledge. Robert Gordon thinks that introspection is too problematic and gives an alternative account which does not rely on introspection. 


\section{Robert Gordon}

Robert Gordon finds that both inference from self to other and introspection are insurmountable problems for the simulation theory. He takes a slightly different approach to own mental state attribution, which is not necessarily in opposition to Goldman's or other STist accounts. He develops a "radical simulation" in which he outlines a way to introspect that is not simply "direct access".

I will describe Gordon's ST proposal in two parts: an alternative to the inference/analogy account, and an alternative to introspectionist self knowledge. The two are connected in an important way because in a simulation, it is not enough to read one's own mental states. At some point, the mental state has to be attributed to the target person. This attribution involves at least the realization that the mental state belongs to the other and a method with which to ascribe the mental state to the other.

\section{Inference}

Gordon thinks that when we simulate, we do not infer to the mental state of the other person. Instead we go through a personal transformation into the other person. He calls this variously "egocentric shift" and "imaginative identification" with the other. He uses the Tees/Crane experiment (done by Kahneman and Tversky, 1982) to illustrate his point. Subjects in the experiment were given this story:

Mr. Crane and Mr. Tees were scheduled to leave the airport on different flights, at the same time. They traveled from town in the same limousine, were caught in a traffic jam, and arrived at the airport 30 minutes after the scheduled departure time of their flights. Mr. Crane is told that his flight left on time. Mr. Tees is told that his was delayed, and just left five minutes ago. Who is more upset? (quote from Davis and Stone (eds.), 1995a, p. 17-18)

Ninety six percent of the subjects in the experiment answered that Mr. Tees would be more upset. Goldman thinks this experiment clarifies the difference between simulating 
oneself in O's situation (the common version of the ST) and simulating $O$ in O's situation (Gordon's version of the ST). When we decide who will be more upset, we make a "personal transformation" so that we "become" Mr. Tees. A personal transformation is a capacity that does not consist in comparing oneself to the target subject. Personal transformation means our own self and knowledge of our own self disappears, to be replaced with knowledge of the target subject, which, in this instance, is Mr. Tees.

To simulate Mr. Tees in his situation requires an egocentric shift, a recentering of my egocentric map on Mr. Tees. He becomes in my imagination the referent of the first person pronoun "I," and the time and place of his missing the plane become the referents of "now" and "here." and I, RMG, cease to be the referent of the first person pronoun: what is imagined is not the truth of the counteridentical, "RMG is Mr Tees". Such recentering is the prelude to transforming myself in imagination into $\mathrm{Mr}$ Tees much as actors become characters they play. (Gordon, 1995, p.55)

Transformation into the other person is not equivalent to making an inference or an analogy. The mental states of the target subject are representations in our own minds of transformation operations we are to undergo in order to transform ourselves mentally into the target subject.

\section{Introspection}

Introspection for Gordon is also replaced by another process by which we come to know our own mental states, called the "ascent routine". This is a necessary replacement for introspection because once introspection is established as the method for self knowledge, inference from self to other follows. The introspection method does not work to determine the mental state of the target subject even if we are imaginatively identifying with the subject. Gordon thinks that if we are committed to introspection as a method of self knowledge, then we are committed to the inference method to determine the mental state of the other. According to the meaning of "introspection", it is only possible to introspect one's own states; it does not make any sense to say that one is "introspecting" 
the states of another person. So, if the STist is commited to self knowledge by introspection, knowledge of the states of another person must be based on some kind of inference or analogy between one's own and other's mental states: "So if an introspection-based methodology is to provide information about another's mental states, then it must do so by inference from one's own." (Gordon, 1995, p.57)

Gordon has established that we do not infer to the target subject. Still, the technique of "personal transformation" needs an additional component which allows a "reading" of the beliefs and desires of the target subject. This reading is done not by introspection, but instead by what Gordon calls the "ascent routine".

The ascent routine works like this: in order to be able to answer a question about a belief that we hold, we get to that knowledge by answering a question about the object of that belief. So to discover our own belief on a subject (e.g. whether Mickey Mouse has a tail) we do not ask ourselves: "do I believe that Mickey Mouse has a tail?" Instead we ask, "does Mickey Mouse have a tail?" The lower order question is about a thing in the world, not about the mental state itself. We do not need to answer any question about our own mental states or even about ourselves. We can discover what we believe by thinking about the world, and not by thinking directly about psychological states. If we answer "yes" to the object-level question, then we believe that $\mathrm{x}$. If we answer "no", then we do not believe that $x$. If we answer neither, then we don't believe one way or another.

Gordon does not have too much to say about how the ascent routine would work for states other than belief. However, knowledge of other mental states can be had also at the object level, so that being able to say, "I want X" or "my foot hurts" does not entail any understanding of the concepts of desire or pain. A child can be trained to say the words "I want" in front of nouns like "banana" or "chocolate milk", but that does not mean that he understands the concepts he is using. Similarly, a child can use the expression "my foot hurts", while thinking that he is describing an attribute of his foot or a temporary condition of his foot which is based on how his foot feels. Use of this 
expression does not mean that the child is attributing something mental to himself. I take his point to be that self attribution of mental states does not entail reference to mentalistic concepts, so when we make self attributions, we are not doing so by introspection. Instead we are talking about various things in the world and prefacing what we think about those things with phrases like "I believe.." or "I want...".

\section{TT Account of Self Knowledge}

In general, the problem for the theory theory is that an explanation of self knowledge that is consistent with the rest of the TT leads to the counter-intuitive position that the same theory that is used to attribute mental states to others is used to attribute mental states to oneself. It seems odd to say that I know what I am going to do next because I have processed information about my mental states as input and given myself my own future action as output. It is just as odd to hold that I draw from that same theoretical body of knowledge in order to determine which mental states I am in right now. My mental life seems to be directly accessible to me, and it is highly counter-intuitive to think that I get at such mental states as fear or loneliness indirectly, by some application of a folk psychology theory on myself.

The position that we use the same calculations on ourselves as we use on those around us is sometimes referred to in terms of first and third person symmetry. In the simulation theory, there is a heavy asymmetry between the first and third person because the methods used to gain knowledge of mental states of others (simulation) is held to be very different from the methods used on the self (introspection or ascent routines). On the theory theory account, the methods used to gain knowledge of our own mental states are

close to exactly the same (depending on which TTist you are) as the methods used to gain knowledge of the mental states of others, i.e. some kind of theory.

Peter Carruthers (1996) exemplifies the typical TT explanation of self knowledge that avoids a behaviourist (or functionalist) reading off of our own mental states. 
Occurrent, or "at hand" mental states (states that are in the moment only such as present pains, perceptions, acts of wondering whether, judging, etc.) automatically trigger the classification of ourselves as being in that state.

Thus, it may be part of the normal functioning of the mind that a mental state, $M$, if conscious, will automatically give rise to the belief that I have $\mathrm{M}$, without all the principles of folk-psychology that play a part in generating that belief being accessible to me. (Carruthers 1996, p.26)

Knowledge of more long term, "standing" mental states (like beliefs, desires, and longterm states that spread themselves over a period of time, and that can be said to influence what we do and who we are) arises when they are in use. We move from our automatic recognition of occurrent mental states to the recognition of the standing states that are producing, or backing up the occurrent states. We have immediate access to occurrent states, and these betray the standing states behind them. My belief that $P$ (long term state) will come out in my judging that $\mathrm{P}$ (occurrent state), and I can therefore figure out that I have the belief that $P$ from the fact that it gives rise to my judgment.

\section{Alison Gopnik}

Alison Gopnik explains self knowledge in her paper "How we know our minds:

The illusion of first-person knowledge of intentionality" (1993). Hers is the strongest and most compelling account of self knowledge and as such is described at length here.

Essentially, Gopnik relies heavily on empirical evidence from developmental psychology to demonstrate that, despite any commonsense intuitions to the contrary, our knowledge of our own minds is not different in a deep way from our knowledge of the minds of others. The theory of mind that we use to understand others is the same theory of mind that we use to understand ourselves.

What is of interest to Gopnik is that children's knowledge of their own mind changes at the same time as does their knowledge of the minds of others. Three year olds 
have the same kinds of difficulties reporting their own mental states as they do in reporting the states of others. They become more proficient after acquiring, at about age four, a representational theory of mind. We develop a theoretical understanding of our own mental states, in the same way and at the same time as we develop a theoretical understanding of the mental states of other people. The sense that we have a different kind of knowledge of our own psychological states is an illusion.

Gopnik is concerned here with our actual experience of psychological states -how they feel to us. This is different from a theoretical or functional understanding of the way psychological states actually work. Of course, a functional understanding of mental states is a basic part of the TT, but what is difficult to explain is our actual experience of those mental states. Our own conscious and continual experience of beliefs and desires, personal moods and preferences, personal historical facts, long-term goals, petty emotions, large-scale emotions, intentions and desires go on "inside our head" and are not accessible to anyone else unless they are communicated through language or behaviour. Also, there is a particular feeling to our own mental states that is different from our experience of the mental states of others. This notion that we have direct and privileged access to our own minds can be construed as a strong claim about the particular relation our experiences have with the underlying psychological states themselves. This claim has something to do with a direct kind of knowledge we have about our own intentional states. This claim about ourselves is transferted to others and their relation to their own intentional states. Gopnik notes that this is an empirical claim about "the cognitive relation between our psychological states and experiences and beliefs about them" (p.2) and as such, should be addressed with empirical tests. Our beliefs about beliefs and how they work is a belief about the particular special relation we have with our own mental states. Gopnik, true to TT form, holds that this understanding is a theoretical construct that we develop to understand evidence about ourselves and others. The question she is 
answering, then, is not how this particular first-person privileged relation works, but why we think we have this privileged relation when in fact we do not.

\section{The Illusion of Expertise}

So Gopnik's claim is that intentional mental states are not known by direct apprehension. Rather, we know we have certain mental states in the same way that we know the mental states of others - they are part of a theory we have that explains ourselves and others. It may be the case that some mental states (such as simple sensations) are known by direct experience, but that is not true for more complex intentional states such as belief and intention. Introspection is not eradicated by Gopnik, it is just shown to be an unreliable and not a privileged source of information for some mental states, and not a source of information at all about the intentionality of other states like beliefs. Neither is Gopnik's claim a behaviourist one, since she acknowledges the existence of mental entities, introspection, psychological experience of mental states, and the "Joycean or Woolfian stream of consciousness" (p.1).

Where, then, does the feeling of privileged access come from? How do we explain that particular very strong belief about our beliefs? "In common sense, intentionality feels like something you perceive, not something you postulate, and the difference between our knowledge of ourselves and others seems profound." (p.3)

Her answer to these questions is that the feeling of direct access to our own mental states is an illusion. It is the same kind of illusion that comes with expertise in any area, where we think we know how we know something, but we are only partly right. Gopnik gives the experience of the master chess player as an example. Master chess players apparently see the game they are playing in terms of forces and powers. They do not decide how to play by looking at the squares and the pieces and calculating what would be the best next move: "they need not calculate that an isolated king is vulnerable; they see he is." (p.10) In the case of expertise, a long history of the use of a theory and 
knowledge of an immense theoretical background are combined with direct experience to produce the sensation that decision-making and action are direct, instant reactions to a situation. A similar kind of experience happens to those of us who are not particularly expert in any one field. Learning how to drive requires memorizing various counterintuitive rules. It was not obvious to me at all which way to move the signal indicator to show whether I was turning left or right - I had to memorize that down meant turn left and up meant turn right. Others have similar experiences with steering and braking. After a certain amount of time, driving movements feel natural and are done automatically. We turn the steering wheel a certain way just because that is the way we want to go, not because we have to check our theory of how a car works. Driving eventually no longer feels like it comes from theoretical knowledge, even though it does. I am expert enough in my use of driving theory to drive across town to a friend's house, and not remember driving there at all. Similarly for learning a sport. Playing pool requires knowledge about how to hit a ball so that other balls will go in certain directions. If you hit the ball with the cue stick in this particular way, the ball will move in that way. If the ball hits the bank at a particular angle, it will go in this direction. After even a little time of using a theory of pool, playing is a matter of strategy, not a matter of how to stand, how to hold the cue and how the physics of pool balls work. As a final example, think of putting names to faces. This is something we have to learn - it is not a directly accessible fact. The name of an extremely familiar person does feel directly accessible, though, when we see his or her face.

In fact we do not directly perceive the king's vulnerability, or the connection between the curve in the road and the direction the wheel turns, or the placement of the eight ball. Those things are indeed perceived - the object is part of a direct perception or experience - but we understand those qualities by relying on a theory, even if that theory is so well used that it has become automatic. We do rely on perception of objects like faces or the number of squares between the king and the knight, and we apply our 
background theory using these bits of evidence that we notice without even noticing that we notice them.

Even though only some of us are experts at chess or baseball, we are all experts about our own mental states. We have lived with our minds and our actions for our whole lives. We experience ourselves (though that might sound odd) every passing minute. This is indeed a long time to practice a skill, and this kind of expertise gives the illusion that we have direct access to our mental states. There really is a huge difference between the knowledge base we use on our own minds compared to the facts we have about other people. We do not see others, even close others, for 24 hours a day, seven days a week. Even if we did spend that amount of time with another, we need to rely on their verbal reports to know about what they feel like and what their history and plans are. Sometimes, even with the disadvantage of a smaller knowledge base, we become semiexperts at predicting or explaining the behaviour of a lover or child in terms of mental states when others are at a loss. These predictions often seem like direct conscious inferences.

The common-sense notion that we have direct access might come from a confusion about the part that is played by perception. Perception is used in conjunction with theory to arrive at a conclusion about mental states, and we have a different kind of access to first-person evidence that is a result of not having to rely on verbal report (we can draw conclusions about our own mental states even when there is no outward behaviour to go on). Gopnik emphasizes, though, that the knowledge we have about mental states does not come directly from that experience. It comes from using evidence garnered from perceptual experience in tandem with a theory.

The fact that we rely on theory for many skills (including mind reading) is especially evident when we make mistakes. For example, if a driver hits a patch of ice, and is not familiar with the notion of steering into the skid, the act of steering suddenly is back to the theory stage. If expertise were a result of direct perception of relevant 
objects, then steering with the skid should be as natural as steering around a corner. Similarly, if a master chess player does not know a particular move, and does not know that a king is in danger because of that move, the king will not "look" weak. The perception of weakness is the result of the background theory, according to which the king is in a weak position. If the player makes an error, then there is a problem with the player's theory, not with the player's perception. The child, who is still an amateur at understanding mental states, makes mistakes about his own psychological states, and in so doing, betrays his dependence on theory. Theories are subject to error, and can be revised in the face of error. Gopnik makes an analogy between scientific theories and how they are constructed and theory of mind and how it is constructed. This claim may be a little strong and problematic, but the idea is that mind reading is a theory to explain ourselves and others. In trying to understand how mind reading works, we should rely more on empirical evidence than on how attribution of mental states feels to us. 


\section{CHAPTER TWO \\ Empirical Evidence for ST and TT}

Empirical evidence from developmental psychology plays an important role in the ST TT debate, because it seems clear to all involved that evidence from experiments done in developmental psychology is directly linked to some theory of mind. The interesting part is that although it is agreed that this empirical evidence is connected to an explanation of intentional ascriptions, it is not yet obvious what the connection is. The result is that each side of the debate take the evidence to uphold its own view.

The examples given here are meant to demonstrate the connection between empirical evidence and the ST vs. TT debate, not to give a full account of the debate as it relates to developmental psychology.

What follows is a short story about how the mind of the child develops with respect to attribution of mental states (this is from Gopnik, 1993). This is a developmental story from the viewpoint of a strict theory theorist, a story about how children learn to read others' minds. A simulation theorist would have different reasons for change in a child's ability to mind-read. For example, she would say that the change is not due to the child's ability to understand representations, but is due to improvement in its ability to imagine the situation of another.

By 18 months there is a rudimentary capacity to distinguish between objects and mental states. This ability is manifested in comments like "oh-oh" when goals are not realized, laughter when an object is played to be something other than itself (e.g. a banana as a telephone), and "no" as a comment about the existence of pretend objects. This ability to refer verbally to mental states improves considerably in the second year. Year three marks the most dramatic surge in ability to mind read. "By the age of 3 , the 
capacity to understand the ontological difference between physical reality and mental states is clearly in place." (p.3)

Three-year olds can understand that mental states of others and perspectives of others can differ from their own perspectives and mental states (e.g. they understand that someone sitting across the table will see the same picture of a turtle on the table except that it is upside-down). They can make judgments about the beliefs and knowledge of others based on what that person knows (e.g. if it is known that an item is in one of two places and the person has already looked in one place, the three-year old will judge that they will know about the item in the other location). They can also understand when someone else is pretending (e.g. they understand the notion of someone pretending to be a dog, yet know also that that person is not a dog), and they can also deceive others through pretense (Gopnik thinks this last may be a metarepresentational ability).

In addition, and perhaps most interestingly, the third year is marked by some dramatic failures in ability to mind read and ability to relate actual objects to mental states that are about those objects. This is demonstrated by the failure of young children

to succeed at tasks such as the false belief task (details to follow). By age four or four and a half, these kinds of failures disappear entirely. There is a definite point in the development of the mind in which children come to understand the relation of objects in the world to their own minds and to the minds of others.

\section{False Belief Task}

The most oft-cited and the most investigated of the experiments in developmental psychology concerns the understanding of false beliefs. Results from the false belief task have been duplicated over and over again in a wide variety of experiments. Results indicate that there seems to be a specific age before which children can not predict behaviours that are a result of a false belief, young children consistently fail to attribute false beliefs to themselves and to others. 
This failure is demonstrated in experiments that run along the lines of the original Wimmer-Perner "Maxi" test (1983). A generic description of the false belief experiment goes as follows:

Two puppets, Maxi and Jane, are watched by a group of children. Maxi puts a chocolate on a shelf and goes outside to play. While Maxi is gone, Jane transfers the chocolate to a pencil box. The question asked the children is: "Where will Maxi look for the chocolate when he comes back?" Older children (those just under five years old) will answer that Maxi will look on the shelf. Younger children (those of about three and a half years) answer that he will look for the chocolate in the pencil box. Younger children have not yet acquired the concept of false belief and the connection of false belief to action. They think that Maxi will look for the chocolate where it really is, while older children think that he will look for the chocolate where he thinks/believes it is.

The false belief task is important because it points clearly and consistently to a definite change in an understanding of mental states, an ability to attribute mental states to self and to others, and an ability to understand the relation between the mind and objects and occurrences in the world. Young children either misunderstand certain problems or at least understand them differently than adults do.

In relation to the debate at hand, have the children acquired a theory or a capability?

\section{TT Explanation of False Belief}

The TTist thinks there are certain key components to understanding a false belief. Taking the information processing mechanisms to be in running order, the child must be able to have the thought:

$$
r_{x} \text { believes that } p^{?}
$$


where $\mathrm{p}$ is faise (e.g., Maxi believes the chocolate is on the shelf). In other words the child must have the concept of belief, rather than just being in a belief state themselves. In order to possess this concept of belief, the child needs to have acquired a theory. Either an implicit theory matures, or a scientific type theory is developed consciously, or both. Either way, children are assumed to have gone through a conceptual change in their understanding of the mind. Most TTists think that the conceptual change is the change to a representational theory of mind.

Gopnik thinks that results from the false belief task and other tests indicate a shift to a representational model of mind. According to her, previous to this shift, children make a division between two kinds of states. There are states like images, dreams, and pretending. These kinds of states do not have a causal relation to the world - they cannot be true or false. On the other hand, states like perceptions, beliefs and desires do have a relation to the world, and that relation is a direct causal one. They are apprehensions of the way the world is, like a copy of the world. With this copy model of how the mind works, mistakes are made on tasks that require a representational model of the mind, or some kind of mediation between our minds and the world.

Understanding misrepresentation (like in the false-belief task or the appearancereality task) means understanding that different people can have different perceptual and intentional relations to the same object. Young children make mistakes about these different relations because on their model of the connection between the mind and the world, there is only total knowledge, which occurs when the world is related to the mind, and total ignorance, when the mind is not connected to the world. This nonrepresentational picture of the relation between the world and the mind does not have any room for variation in degrees of belief about the world, variation in sources of belief, or for false beliefs. Although a non-representational view will carry children through many kinds of predictions and explanations, eventually a representational view is needed to explain the recurring cases of variation in people's cognitive relation to the world. 
Children come to understand that beliefs and desires are what we think about things in the world - they are not the things themselves. (Gopnik, 1993 p.6):

Rather than distinguishing different types of mental states with different relations to a real world of objects, the child sees that all mental states involve the same abstract representational structure. Many characteristics of all psychological states, such as their diversity and their tendency to change, can be explained by the properties of representations. This unified view provides predictions, explanations, and interpretations that were not possible earlier.

(Perner (quoted in Stone and Davies, (eds.), p37):

[B]y interpreting statements and determining what they refer to, children are constantly exposed to the process of interpretation and reference. And so, helped by pretense and the observation of correspondences in their attempt to understand these instances of representation, children will eventually hit on the concept of representation as their common denominator.

\section{ST Explanation of False Belief}

The simulation theorist has a different conception of the ability to understand false beliefs. In order to get to a false belief, we need to have the ability to think: "I believe that $p "$ or simply, "p", while imaginatively identifying with another person. In other words, we do not need to be in possession of the concept of belief, we just need to be capable of having beliefs ourselves.

The change evident in children's understanding of false belief is a change in ability. Children get better and better at imagining the situation of another person, and at identifying with others. This development is accompanied by (is a part of) the development of information processing mechanisms. When children are young, they have not yet mastered the ability to identify imaginatively with other people. They are still making the egocentric mistake of referring only to their own perceptions and beliefs. As they grow older, they acquire the ability of taking into account the differences in beliefs, etc. between themselves and other people. 
Robert Gordon (1986) attributes the mistake to egocentric bias. The child's predictions are based on how things actually are (which is determined by how the child thinks they are). "One may even say that the young child attributes knowledge - by default - before she has learned to attribute belief". (p.69) If it were the case that children acquired the concept of belief by learning some set of rules, then it should be impossible for children to predict any human actions at all before those rules have been internalized. It should also be the case that after the rules have been learned, there should be no difference between understanding true belief or false belief; the whole thing should develop as a single package. Simulation theory, however, explains the false belief evidence. Ability to make assertions while simulating eventually overcomes the tendency to egocentric bias that is evident in young children.

Paul Harris (1991) points out that just the act of thinking " $p$ " while identifying with someone else can be a complicated procedure. There are a number of "default positions" (p.289) that need to be overridden: both states of reality and the intentional states of the self towards reality need to be adjusted. In some cases, it is only one or the other of these default positions that needs to be adjusted. In difficult cases, such as the false belief case, children need to override both positions. They need to be able both to input beliefs and desires into their decision-making system that do not belong to them and they need to be able to read the output off-line. Also, Harris points out that some people are more difficult to simulate than others. Simulation failure on the false belief task at a young age occurs because the task is too complex.

\section{2nd Order False Belief}

There is much literature on both sides of the debate that can "save the data" with regards to the various false belief tests. Perner and Howes (1992) develop an experiment that would instead (they think) confirm or disconfirm predictions based on ST accounts 
and TT accounts. The experiment is a higher level version of the Wimmer-Perner false belief test. In this experiment, children are told a story in which John and Mary are unpacking their bag of chocolates together. Mary has to go to the library, so John is left to put away the chocolate. He tells Mary he will put it either in the top or bottom drawer. When she leaves, he puts it in the top drawer, then goes out to the park to play. While John is gone, his mother moves the chocolate from the top to the bottom drawer. The children are then asked three questions about John's belief and John and Mary's concept of that belief. The first question concerns John's false belief:

Q1. Where does John think the chocolate is?

The second question concerns John's self-reflection:

Q2. If we go to the park and ask John: "Do you know where the chocolate is?" what will John say?

The third question concerns Mary's reflection on John's knowledge:

Q3. If we go to the library and ask Mary: "Does John know where the chocolate is?" what will Mary say?

Perner and Howes thought that predictions about the ability to answer these questions made by the theory theorist would be markedly different from predictions made by the simulation theorist. According to the simulation theory, in order to answer Q1., the child just has to think "p" and simulate John. The same is true of Q2. If the child is already simulating John's false belief that the chocolate is on the shelf, she is also at the same time simulating John's conviction that it is so: "The reason for this is that the child is presumably simulating a conscious belief, and the believer's reflective conviction that he is right is simply part and parcel of a conscious belief." (p.167) The third question, however, will be more difficult because it involves thinking "p" and simulating Mary, who is in turn thinking " $\mathrm{p}$ " and simulating John - it involves a simulation of a simulation, and must be done in addition to the first simulation already practiced. 
In contrast, use of a theory to answer the questions will mean that the first question will be easy for the children since it is a first-order representation of the character's mental state (John thinks the chocolates are in the top drawer), while the second two will be difficult since they involve second-order representations (e.g. John thinks John knows, Mary thinks John knows).

Based on the predictions made by Perner and Howes, the test results were in favour of the theory-theory, since children had much more difficulty answering the last two questions. The question about where John thinks the chocolate is was consistently easier for children to answer than is the question about what John thinks he knows.

These test results are difficult for the simulation theorist to explain. However, in his reply to Perner and Howes, Gordon points out that children may be tripped up by the fact that their own doubt about the correctness of Jon's knowledge may infect their introspection as John. Since they have reasons to believe that the chocolates have been moved, they put those reasons on John. Or, children may attribute uncertainty to John based on what they themselves know about how the chocolates keep being moved around: "John might reason, "I forget where I put things; and besides, Mlom often moves them anyway! So now I don't know, at most I only believe." (p. 188)

Gordon also points out that any experiment is suspect in which children use the word "know" to describe a situation (e.g. Maxi knows what is in the box). The word "know" can be used without an understanding of the concept of knowledge or an understanding of the sentence "x knows that $p "$; it does not take much training to preface an assertion about the world with the statement "I know that...", or "she knows that... Use of the word know or of the formula, "I believe that" does not entail understanding of knowledge or belief, and it certainly does not imply an meta-representational capability. In the same vein, children may answer questions incorrectly about what other people know simply because they don't yet know what "know" means, not because they don't know whether or not the other person knows something. They might fully understand that 
if someone has access to $X$ visually or verbally, they can use information about $X$ in future actions. (Gordon gives as an example his three and a half year old son imploring his mother: "Don't tell Bea I [had an "accident"] - she'll tell everybody" (1995 p.181)

\section{Other Tasks}

There are several other kinds of experiments in developmental psychology that test the ability of young children to mind read. The most common of these can be grouped into three types of task: the appearance-reality task, ways-of-knowing, and subjective probability. I will describe each of these in turn.

\section{i) Appearance-reality task}

The appearance-reality task involves an object that looks like something other than it is. Young children consistently maintain that what the object is and what the object look like are the same thing. For example, children are shown a sponge that looks like a rock. Before the sponge is examined, children say it is a rock. After they examine it they say both that it really is a sponge and that it looks like a sponge. Other objects that are obviously deceptive (e.g. a white cat with a blue filter over it) is said to both look blue and actually be blue, no matter what lengths are gone to by the experimenter to show that the cat really is white. Similarly, children will say that a person who looks through the blue filter (while the child does not) thinks that the cat is white.

The appearance-reality task is interesting because it is the kind of experiment that demonstrates most effectively (for the TTist) the symmetry between children's learning to attribute true beliefs to themselves and attributing true beliefs to others. Children make exactly similar kinds of errors when asked about their own (and own just past) beliefs as they do when asked about the beliefs of others. Another telling example involves a smarties box filled with pencils. Before they look in the box, children answer "Smarties" when asked what they think is in the box. After they look in the box, the same children 
consistently say that they thought there were pencils in the box, even when they said there were Smarties when first asked minutes earlier. This is parallel to the answer they give about other's beliefs about pencils in Smarties boxes. They consistently say that the other person will think (previous to looking in the Smarties box) that there are pencils in the box.

Interestingly, in experiments where children are asked to report on past mental states that have since changed and are not belief states (specifically, pretenses, perceptions, desires and intentions) they are more likely to report those states correctly (see Gopnik and Slaughter, 1991). They are most likely to correctly report on past pretenses and perceptions (i.e., states that either do not have a causal connection to the world or that are not mediated by representation or propositions), and less likely to report correctly on direction-of-fit states like desire and intention (i.e., states that demand a representational model of the connection between mind and world), both for themselves and others.

In any case, it is significant that there is a parallel between children's understanding of their own immediately past mental states and the states of others. Somewhere between the ages of three and four, a representational explanation of (at least) intentionality (own and others) is developed, and that is a different explanation fromthe one held earlier.

In many of these types of tests, "own mental states" for children seems to refer only to past beliefs and desires, not current ones. Some simulation theorists (notably Paul Harris and Alvin Goldman, see Harris (1992) and Goldman (1993)) point out that errorless performance in reporting current mental states would be a problem for a theoretical/inferential account of self knowledge. They claim that a past self could be construed as a different thing from a present self - an entity that is closer in kind to other people than to the self. Memory decay distances the present self from the past self so that questions about the past self are answered using the same techniques that are used to 
answer questions about the mental states of others (i.e., simulation), rather than the techniques used to answer questions about the self (i.e., introspection). The fact that children do not seem to have any trouble answering questions about their present psychological states ("Are you hungry?" "What do you think is in the box?") supports the simulationist claim of asymmetry between first and third persons.

Alison Gopnik responds to this criticism by pointing out that to the theory theorist, answers to questions about current mental states are not helpful because they are taken to mean that what is wanted is a report of the world as it is in that moment. So for example, the question, "what do you think is in the box?" is taken as being the question, "what is in the box?" These kinds of questions can be answered by relying on a "copy" theory of the world and are not helpful in determining the extent of the child's representational theory of mind. There still are some experiments, however, in which children do seem to recognize the difference between what they (presently) think about the world, and the way the world is (they know that when they are pretending to drink juice that they are not actually drinking juice). This ability fits in with the distinction given earlier between "pretend" states and real states.

Also, children give equally accurate reports about other people's current states. Young children are still relying on a "copy of the world" theory, which deals well with true beliefs. They can report accurately on their current beliefs about the world because those beliefs are equivalent to how the world is (e.g., the world is a place where smarties are in smarties boxes, or a place where pencils are in Smarties boxes). The reason for the emphasis on past mental states, is that the experimenter is interested in false beliefs, bence the question, "what did you think was in the box?" Young children's prerepresentational theory fails them when it comes to past beliefs.

Gopnik also points out that these past beliefs are only half a minute to a minute in the past. Equating the self 30 seconds ago with other people, whose experience we have to simulate is a stretch. Memory does decay, but it seems unlikely that it would decay that 
much in 30 seconds. "Try it at home: the certainty of your 30-second-old belief seems as phenomenologically secure as your current beliefs" $(1993$, p.93)

Finally, Gopnik writes that any questions that require a representational theory of mind are answered incorrectly, even when they concern a present mental state. For example, this is true for current mental states in the appearance-reality test (rock/sponge). The child is asked (after examining the sponge), "what is this?" and "what does this look like?" They answer the second question incorrectly (they say it looks like a sponge, or a white cat, or whatever), even though it refers to an aspect of their current mental state.

In another set of experiments, children have difficulty identifying the source of their own beliefs (they cannot say whether they know something because they saw it, heard about it or touched it). Ability to answer questions about themselves on the falsebelief task, the appearance-reality task and the subjective probability task was found to be significantly correlated with ability to answer questions about others on those same kinds of tasks. (See Gopnik and Astington 1988, and Moore et al. 1990).

\section{ii)Ways-of-knowing (or sources of belief)}

Source of belief refers to the inability to locate where a belief comes from or to understand the link between, for example, seeing and knowing or inference and knowing. For example, young children do not infer that someone who has seen or touched an object would know what it was, while someone who did not have perceptual access to the object would not know what it was.

The original experiment of this sort comes from Wimmer et al.,1988. In this experiment, a child sits across the table from another subject. Between them is a box filled with something familiar (e.g., a toy car, a chocolate, a comb, etc.). Previous to any questions, either the child or the other subject had access to what was in the box. Either they were allowed to look in the box or they were told what was in the box by the 
experimenter whispering in their ear. The child always saw when the other subject had access to what was in the box. After either one or the other had looked/been told what was in the box, the child was asked knowledge questions, e.g., "do you know what is in the box or do you not know?" and "does [name of other subject] know what is in the box or does he not know?". Consistent with other types of experiments, young children answered incorrectly while older children got the answer right, For example, after having watched the other subject look into the box, young children would answer that the subject did not know what was in the box.

According to the TTist, the child has not yet completed her folk psychology theory, and has not yet added on the part which says that people know that $\mathrm{p}$ by seeing or knowing that $\mathrm{p}$.

Perner and Howes (1992) think this experiment is not consistent with ST based predictions. If the child gets to look in the box and the other subject does not, a simulation should make the knowledge question easy. All the child has to do is simulate herself looking at a closed box to come up with the answer, "don't know". The kind of situation in which the other sees, but the child does not should be more difficult on the simulation account. Since the child can not see in to the box, she does not have any input at hand to feed in to her processing system. She does not have knowledge herself of what is in the box, and so cannot generalize to the other person's situation and attribute the "don't know" response to them. In fact, questions for both scenarios were equally difficult to answer.

The simulation theorist, however, thinks that this data is not necessarily consistent with the TT view. Gordon's worries about asking children knowledge questions (mentioned above) apply here. Paul Harris (1992, p. 221) thinks that claims made by the TTist based on the source of belief task is inconsistent with the claims they make based on the false belief task. Since children are stingy with their attribution of knowledge to subjects about what is in the box, they should be equally stingy with their attribution of 
knowledge to Maxi the puppet with regards to Maxi's knowledge. Maxi, like the subjects in the sources task, has given no clear indication of her knowledge of the location of the chocolate. Maxi has either just seen or has been told where the chocolate will be. If the two test results were consistent, the children should attribute the state, "don't know" to Maxi, rather than a state of knowledge. Secondly, Harris points out that this type of data has been difficult to reproduce, and has even in his opinion been reversed in the type of experiment done by Pratt and Bryant (1990), in which young children can say which of two people know what is in the box when one of them has looked in it and the other has not.

A related kind of test is referred to as "subjective probability". This kind of test documents the indifference young children hold towards sources of information. They do not prefer getting information from someone who says they know something rather than someone who says they are guessing or only think they know. Sources of belief and subjective probability experiments indicate that young children do not understand the concept of degrees of belief.

Finally, there is interest in spontaneous explanation given by children with reference to their mental states. At three years there is almost no genuine reference to belief or knowledge, and loads of references to desire and perception. References to belief or knowledge increase dramatically with age, as does performance on false-belief and appearance-reality tasks. Improvement on those tasks is strongly correlated.

\section{Autism}

Another battleground for the ST and TT debate concerns the causes of autism. Autism, like schizophrenia, is a difficult disability to define. Autism is characterized by a cluster of symptoms, which, in some combination are sufficient, but not necessary for a diagnosis of autism. There are three more specific impairments, however, which are agreed as being universally present in some degree or other. They are: specific 
abnormalities with regards to social behaviour, especially with regards to empathy and reciprocal relating; communication problems (both verbal and non-verbal); inability to engage in pretend play or role play due to lack of creativity and imagination, this inability usually resulting in repetitive, rigid behaviour. There are a host of other impairments, including language-related difficulties. It even has been found that non-autistic relatives of people with autism (e.g., a twin) have problems with social relations and developmental problems, especially as related to language development. (Boucher, 1996) Autism is especially interesting to theorists of mind because it seems to be an impairment that is directly related to the ability to attribute mental states to self and others. There is an inability to treat other people as subjects with their own point of view, to understand such mental states as belief or desire, etc. Many of these inabilities (apart from the inability to pretend) are the same kinds of inabilities that young children display in such tasks as the false-belief task and the appearance-reality task. What is the specific disability that causes autistic children to fail in their understanding of other minds in the same way that the three year old fails?

The theory theorist takes this evidence to point clearly towards the inability to represent beliefs, desires, etc., which in turn indicates a lack of a theory of mind. This lack may be a result of damage to the theory of mind "module". It is interesting to speculate on the connection between the theory of mind module and the language module, which also seems to be damaged in people with autism. In any case, people with autism, according to the theory theorist, never go through the conceptual stage necessary to acquire a representation theory of mind. Instead, for some reason, they stay in the "copy theory" stage, just like children under age four. This hypothesis seems to be backed up by similar kinds of false-belief tests (etc.) that were run on young children. For example, a very high number of autistic children aged 6 to 16 failed a version of the Wimmer-Perner Maxi test, while children with Down's Syndrome almost all gave the 
correct answers, even though children with Down's Syndrome generally have a lower IQ level than autistic children.

On the other hand, simulation theorists think that inabilities connected to autism are directly related to an inability to simulate. Mental simulation involves a level of pretending, and the failure to master the concept of belief is directly related to the inability to pretend. It is well documented that people with autism are not able to engage in pretend play or in role taking. This is where they differ from children. On the simulation account, children are learning to use the simulation method, and they learn this by practicing to be things other than themselves. They are learning to imaginatively identify with others and to simulate other people's mental states. Autistic children lack the capacity to pretend, and so never learn to simulate. The inability to simulate results in inability to relate to others in a social situation, to empathize or to reciprocate.

\section{Evidence for Error in Self Attribution}

There are many experiments in psychology that demonstrate that we are often in error about our own mental states. We have difficulty explaining why we did something (e.g., the right-hand bias described in the previous chapter), we can be easily persuaded to attribute often ridiculous mental states to ourselves such as the ability to detect false suicide notes (explained later), and our verbal reports of our inner states are shown to often be in conflict with our outward behaviour.

This evidence would seem to be a blow to the simulation theory for several reasons. To begin with, we are supposed to be able to have direct access to our mental states. If there is in fact a discrepancy between our self-description and our behaviour, that would seem not to be the case. Error in self attribution would fit better with the view that there is a first/third person symmetry with regards to mental state attribution. Also, error in self attribution accords with the argument of cognitive penetrability (outlined 
earlier) in which it is shown that it is theories that are defeasible. If mental state attribution is just an (automatic) process, then it is more difficult to explain error.

The STist response to these challenges will be discussed in detail in the following chapter. In general, the STist will claim that there is some deficiency in the decisionmaking system, or that it is not programmed to handle certain kinds of simulations, like purely physiological simulations, or that error is a result of a lack of input information.

The following two experiments are from Nisbett and Ross' Human Inference (1980).

In one scenario, office workers were sold a lottery ticket for $\$ 1.00$. They were either just handed a ticket by the experimenter or they were allowed to choose which one they wanted. The next day, the experimenter asked to buy back the tickets, and the office workers were allowed to set the price. The results of this test are always found to be surprising. Almost no-one who is asked to predict the results can do so, even though the test has been replicated a number of times, each time with the same results. For example, one of the experimenters has asked his entire undergraduate classes each year for several years in a row to predict the results, and almost no-one is capable of correct prediction. The subjects who had their tickets handed to them asked for an average price of \$1.96. Those who had chosen their tickets asked for an average price of \$8.67. What is of interest is that no one can predict these results, yet it has been demonstrated a number of times that this is how people in this situation will behave.

A second test studies the phenomenon of "belief perseverance". In this test, subjects are persuaded (e.g., by answering a questionnaire) that they have a specific trait that they would never have considered themselves to have, such as the ability to detect false suicide notes. Even though immediately after the subjects were told they had this trait they were given evidence that disconfirmed the initial results (e.g., they were told the test results belonged to someone else or that it was not a real test), it was found that the 
subjects continued to strongly believe that they still had this trait. The same belief perseverance was found in subjects who were only watching the experiment. 


\section{CHAPTER THREE \\ The Role of Functionalism in the Debate}

Simulation theorists such as Goldman, Heal and Gordon often refer to TT as functionalism, and theory theorists like Gopnik refer to themselves as functionalists. Why is this? Are they equivalent? Functionalism is a view which determines what mental states are by what they do and how they work in a system. TT is a view about how we attribute mental states to ourselves and to others. TT is not functionalism. It is, however, functional ist or at least consistent with functionalism.

TT postulates internal mental states based on external evidence. It individuates mental states by way of their functional role, so that the place of the belief "it is raining" is amongst other psychological terms (causally linked to them) and also causally linked to actions. The belief "it is raining" is that state by virtue of its being caused by , for example, seeing rain, by it leading to other states, such as the desire to stay indoors, and by its causing certain behaviours, such as wearing a raincoat. It is a postulated mental state that fits in with a bunch of other things that are all related to each other causally. The theory of that belief state could be manifested in a series of lawlike generalizations (when $\mathrm{x}$ says, "its raining" then $\mathrm{x}$ believes that it is raining; whenever $\mathrm{x}$ sees rain, $\mathrm{x}$ believes that it is raining, etc.) or it could belong to a general body of knowledge represented in some non sentential way. No matter. Whatever a "belief" looks like, it is a thing which causes certain actions, causes further beliefs and other internal states and is caused by certain environmental effects. The fact that the TT understands behaviour by placing mental states in causal relations with inputs, outputs, and other mental states makes it a functionalist theory.

Theory theorists are often accused of being behaviourists because they postulate mental states based on observable behaviour. Although intrinsic qualities do not play an 
essential role in attribution of mental states in the TT, TT is not a behaviourist theory. Behaviourism equates mental states with external observable behaviour, while TT assigns internal states to other people to explain and predict their actions.

Fodor (1996) illustrates the difference between behaviourism and functionalism by describing a behaviourist coke machine and a mentalist (functionalist) one. Both machines give a coke for ten cents. Both are described in terms of causal relations between states. However, a behaviourist machine is a single state machine - if you put a dime in as input, it spits a coke out as output. If the machine is a more complex one that gives change, waits for more money, etc., then its states can be defined in a functionalist way. State $l$ is the state in which a) given a dime, it dispenses a coke, and b) given a nickel it dispenses nothing and proceeds to State 2 . State 2 is the state in which a) if given a nickel, it dispenses a coke and returns to State 1 , or b) if given a dime, it dispenses a coke and a nickel and returns to State I. Put together, State I and State 2 mean that the machine will dispense a coke if given a dime, dispense a coke and a nickel if given 15 cents, and wait for another nickel if given a nickel. The machine is functionalist and not just behaviouristic because interdefined internal states are part of the explanation for how it works.

TT, however it is construed, is a functionalist theory. Mental states in the TT are causes or results of behaviour ("She ignored him because she believed that he had ignored her earlier and she wanted to get even") and are interdefined by their causal relations to one another as well as to their external causes and effects. TT postulates internal mental states according to what they do and what causes them and how they are causally related to each other. It does not a) assert their existence based on their phenomenological qualities or $b$ ) equate them with externally observable response to stimulus/inputs.

Is it possibie for ST to be a functionalist theory also? ST could postulate the existence of internal mental states in others based on observation of behavioural 
stimulus-response combined with knowledge of how our own internal states affect response to stimulus in our own case. It also relies on internal mental states for understanding and prediction of behaviour, or at least it refers to states such as fear, belief and attention in an explanation of movement and action. The difference is that ST is a capability in which the internal mental states that are used to describe and predict behaviour are discovered first and foremost by introspection, and thus are not postulated to explain observable behaviour. Internal states are "directly accessed" -- they are known by their intrinsic qualities. What is postulated in ST is that others have minds that work like our own. Internal states on the ST account are not identified by their causal relations to each other and to external causes and effects, even though they are thought generally to be in relations of this sort. Does the fact that the base for our knowledge of the mental states of others (and ourselves) is phenomenological rather that theoretical mean that ST is not a functionalist theory?

Perhaps ST could be construed as a functionalist theory if internal states were still defined by their causal relations to other states, but are initially recognized by their intrinsic feel. This way, the ST theorist could be both a functionalist and believe in understanding mental states by their intrinsic feel. What is wrong with combining a functionalist type understanding of other minds with an inference based on intrinsic qualities? Bertrand Russell does something like this in his paper, "The argument from analogy for other minds" (1948). We notice by self-observation and intrinsic feeling of mental states that a particular state $A$ is always connected to a particular behaviour B. So we notice that the feeling of thirst is always connected to our saying: "I'm thirsty". We then notice the same behaviour in others (we hear them say "I'm thirsty") and accordingly postulate the same kind of cause (or at least postulate thirst as a possible cause, since there are a number of possible causes). The behaviour of those around us seems quite similar to our own behaviour, and so it is natural to postulate similar kinds of thoughts as causes for actions that we ourselves have carried out. 
From subjective observation I know that $A$, which is a thought or feeling, causes $B$, which is a bodily act, e.g., a statement. I know also that, whenever $B$ is an act of my own body, $A$ is its cause. I now observe an act of the kind $B$ in a body not my own, and I am having no thought or feeling of the kind A. But I still believe, on the basis of self-observation, that only A can cause B. I therefore infer that there was an A which caused B, though it was not an $A$ that $I$ could observe. On this ground I infer that other people's bodies are associated with minds, which resemble mine in proportion as their bodily behaviour resembles my own. (Russell, 1948, pp.312-13)

Russell's argument seems to combine functionalism with the knowledge of mental states from a kind of simulationist introspection/ inference. He posits causal laws in which our own thoughts and feelings are relevant, because they lead to the inference that other minds are analogous to our own. The difference between Russell's introspection/ inference and ST is that ST makes the inference to the other by some kind of imaginative identification. This differs only slightly from Russell's account because presumably, the idea that we can identify imaginatively in the first place comes from some notion that other people's minds resemble our own to a sufficient degree. Russell does base his theory on observed inputs and outputs. For example, if he enters as input the instructions to his student: "write me a paper on Descartes' reasons for believing in the existence of matter," he will elicit the output of paper writing activity. Thus, Russell makes a postulation about internal states based on outward behaviour, and on the causal relations between internal states and stimulus and response. ST is supposedly not based on a theory in this way - it is based on running a program through a similar kind of system.

There is major problem with the Russell-type account that prevent it from being a viable alternative to a straight TT view of mental state attribution. Russell attempts combine his own experience with some kind of functionalist account of the causal role played by internal states. Although it is the case that we do all have experience with these mental states we are postulating, it is a fallacy to try to use our own experience to form a 
theory about other minds in general. It is a bad argument to claim knowledge of thoughts and feelings based solely on direct experience with one's own case.

It would seem at this point that we can either have a functionalist theory of mental states and no intrinsic qualities (or rather, no central role for intrinsic qualities) or a central role for intrinsic qualities and no functional theory. Alvin Goldman believes this to be true. Since he thinks that the phenomenological qualities of mental states are essential for an understanding of our own mental states he argues against a functionalist understanding of our own mental states in his article, "The psychology of folk psychology". I will outline his argument then discuss what kind of role intrinsic qualities can play in folk psychology and whether he has successfully eradicated functionalism in this area.

\section{Alvin Goldman}

Goldman's main concern in his article, "The psychology of folk psychology" (1993) is to explain how the ordinary person (i.e., non-scientists and non-philosophers) understand or experience their own mental states. How do we understand and make use of mental words? What are we doing when we give verbal labels to mental states? And how does that process work? He makes it clear that the answers to these questions will be in psychological, not scientific terms. He has no quarrel with the (neuro-) scientific hypothesis that mental states actually have functional properties - properties that can be explained in terms of causal relations between inputs, mental states, and outputs. He does have a quarrel with the kind of psychological functionalist hypothesis that he calls "representational functionalism" - the claim that regular folk represent mental states to themselves in functionalist terms or for functionalist reasons. He argues that representational functionalism (RF), though it might explain the underlying structure of mental states, does not explain how those mental states are represented to, and used by, the subject. In other words, he has a quarrel with the TT account of self knowledge. His 
central thesis is a negative one - that functionalism does not work. He offers an alternative explanation in simulationist terms.

I will begin, as Goldman does, with some vocabulary. He thinks a general understanding of intentional states works something like the following:

When we hear a particular mental word, we understand it by matching it to the category that word represents. The category representation (CR) is a general representation stored in long-term memory. The CR gives what we know as meaning to the particular word. The subject understands a particular mental word by associating it with this category representation. The structure of this representation is unimportant in this account, but might be something like a list of features that are individually necessary and jointly sufficient to give meaning to a word, an ideal instance, or some kind of connectionist network, etc.

We understand the meaning of a word (and so can apply it to ourselves) by matching an instance representation (IR) of our current state to the category representation. Goldman explains:

The content of such an IR will be something like, "A current state (of mine) has features $\$ 1, \ldots, \phi n$." Such an IR will match a $C R$ having the content: $\phi 1, \ldots, \phi n$. Our aim is to discover, for each mental word $M$, its associated $C R$; or more generally, the sorts of $C R s$ associated with families of mental words. (1993, p.16)

The question he asks is how the $\mathbb{R}$ is matched with the $C R$ in order to get the appropriate categories.

One answer to that question is the functionalist account of mental states. Goldman thinks that the most precise formulation of the TT account is functionalism. That formulation is the target of his criticisms.

In a functionalist account, contents of mental states are understood in purely relational terms. There is not an intrinsic definition of mental states. Three kinds of relations are possible: (a) relations of inputs to mental states, (b) relations of internal 
mental states to other internal mental states, (c) relations of mental states to behavioural outputs. These relations are variously described as causal relations or transitional relations. An example of an understanding of a mental state in relational terms is: hunger is produced by lack of food (a), it causes a desire to appease the hunger (b), and it causes the subject to go and search for food (c).

Goldman wants to know if a functionalist method of applying mental states to ourselves is psychologically plausible. In CR-IR terms, self knowledge goes like this: "Thus [functionalism] implies that a person will ascribe a mental predicate $M$ to himself when and only when an IR occurs in him bearing the message role $F(M)$ is now instantiated. (p.17) Goldman asks: does the subject actually have all that functional information at the occurrence of the mental state? (Does the subject have functional-role IRs to match with functional-role CRs?). Three specific problems with the functionalist account lead to a negative response.

The first two problems have to do with ignorance of actual and possible causes and effects of mental states. How does the functionalist explain awareness of states in cases where there is no information about preceding and successive states? For example, how do we know we have woken up with a headache when we are not aware of the causes of the headache, and we have not yet acted out the results of the headache (e.g., looking for aspirin). Our knowledge of this state seems to be immediate. Also, information about counterfactual properties is difficult to obtain. For example, a possible successor behavioral result of thirst would be to reach out my arm to get a glass of water if a glass of water were in arm's reach. It seems as though a mental state can be identified as such only if it is connected to all the possible successor states (which are infinite) as well as to all the actual ones.

The third problem with a functionalist account is the problem of combinatorial explosion. Each state is defined by the kind of relation it has with other states, which in turn are defined by the kind of relation they have with other states and so on. The 
problem here is not one of infinite regression, since eventually there are relations to specific input and output actions, and these are understood independently of the relations to mental states. The problem is an overload on the number of relations that have to be computed by the brain in order to understand the mental state at hand. The complexity of the relations of states to other states grows exponentially with every relation that needs to be defined in order to understand the initial mental state.

In answer to these problems, Goldman suggests on behalf of the functionalist the solution of "partial matching", in which IRs are recognized before they completely match the CR. I imagine this is something like recognizing a piece of music by the first few notes, or computer word processors that finish words as you type by recognizing the first few letters of words that are used frequently. This solution would also go a long way towards explaining error - the brain jumps ahead to match an $\mathbb{R}$ but results in a mismatch because information is incomplete.

A more refined (according to Goldman) solution might be to modify the account so that the functionalist properties of mental states are inferred from their intrinsic (nonrelational) properties. In other words a viable functionalist account would include the qualitative feeling of internal states. So we first recognize the feeling of hunger and then (through training) are able to identify between the state of hunger and: effects such as walking over to the refrigerator, links with other states such as the desire to get food, and origins such as missing breakfast. We know that property $E$ has functional role $F$ - we know the functional role of any given state by first identifying its non-relational property and then connecting it to its particular functional role. This solution is similar to the one outlined by Carruthers in ch. I.

Goldman thinks, though, that this account of functionalism just pushes the essential problem with functionalism back to the learning stage. How do we learn the connection between the non-relational intrinsic quality of a state and its functional role in 
the first place? We still do not have an understanding of how we originally attached the intrinsic property to the functional role.

By intrinsic properties, Goldman means a particular qualitative "feel". (Note: Goldman is just talking about sensation predicates here, like perceptions and bodily sensations. He addresses propositional attitudes later on). Neural properties are intrinsic, but they are not what we detect consciously when we identify a mental state, even though neural activity may be the cause of a mental state. The intrinsic properties of mental states are how they feel - qualia. Our mental words are for qualitative properties of mental states. A physiological analogy for the qualitative properties of mental states would be something like the qualitative properties associated with low blood sugar levels. When we describe the feeling of hunger or of a "sugar high", the folk psychological descriptions we use do not include words like "glucose level" or "insulin output", even though those words indicate the physiological cause of a particular bodily sensation. We use words like "craving" or "hungry" or "starving" that describe how low blood sugar level feels. Similarly, mental words describe the resuit of neural activity, and that result is a particular sensation, like pain.

At this point, Goldman thinks that it is most parsimonious to drop the functionalist component of the mental state model altogether: "Does it make sense, however, to regard an instance of a qualitative property as a representation of a mental state? Is it not more accurate to say that it is a mental state, not a representation thereof?" (p.21) Now qualia themselves make up the categories in CRs instead of being the link between the functional role categories of CRs and IRs and qualitative feels. In this new model, there is only a category of feels, and instances of a feel. The IR label can now be changed to simply I, since it no longer is a representation of a state, but is itself a state. Now instead of being an instance representation, it is simply an instance. We just learn the feeling and the word for the feeling. Self ascription, then, is the instance (the state) matched to the $\mathrm{CR}$. 
What is a qualitative feel? Let us be clear here about Goldman's understanding of a qualitative feel, since his is the most explicitly formulated ST account of self knowledge via introspection. We detect qualitative properties, or qualia, "directly". These properties are intrinsic and categorical.

The sensations of pressure, A-flat, orange, or sour, for example, are sharply different in experienced quality ... This use of the term quality refers to differences across the sensory domains, or sense modalities. It is also meaningful, however, to speak of qualitative differences within a modality, for example, the difference between a sour and a sweet taste. (p.21)

Of course, most experiences are made up of more than one quality. Pain can be at various locations, it can be throbbing or stinging, etc. The kinds of feelings that are associated with the word "pain" are many and varied. This variation is reflected in the contents of the CRs -- the mind is able to detect the various qualities that make up a single experience, and classifies the qualities accordingly. A person in pain would not necessarily be able to identify verbally the various components of his experience of pain, but his mental system could divide the experience into various sub-systems which would match up with the relevant $C R s$ that represented, e.g., stinging, grinding, shooting, intensity, location, etc.

It is easier to understand the kind of account in which mental states are simply recognized by how they feel when the mental states are states like emotions or bodily sensations. But how do we recognize an intention to do something? What does a belief that it will be sunny tomorrow feel like compared to a hope that it will be sunny tomorrow? It is not so obvious that propositional attitudes are recognized by how they feel. Goldman tackles this problem in two parts - how we recognize attitude types and how we recognize attitude contents. Attitude types are states like believing and hoping. Attitude contents are what the attitudes are about. For example, believing that it is going to rain and believing that the Blue Jays are going to win are two contents of one type of attitude. 


\section{l.Attitude types:}

Goldman has three arguments in support of a recognitional account of attitude types.

First, Goldman thinks that attitude types - beliefs, thoughts, etc. - do have a qualitative feel, even if that feeling is "thinner" than the feel of an emotion or sensation. For example, the tip-of-the-tongue experience does not have a specified content (the content is an absent word), but it has a definite phenomenological quality, even if that phenomenology is not sensory. Second, Goldman thinks that there is an argument in favor of the experiencing of propositional attitudes that is parallel to Jackson's (1982) argument for experiencing qualia. Just as Mary, the scientist who lived in a black and white world, studied the experiencing of colour and understood colour in a functional way but did not know what it was like to see a red thing, there is a "what it is like" to propositional attitudes. Someone may study the phenomenon of desire, and understand its causes and effects, be able to predict its occurrence, and predict the actions that would result from that mental state, etc., but there would still be something missing from that scientist's understanding of the mental state of desire - what it feels like. Finally, Goldman argues that we know that attitude types have a certain feel because we are able to detect various strengths to our beliefs, likes, hopes, desires, intentions, etc. We even have vocabulary for the differing intensities of attitudes. For example, the attitude of liking can be classified into the different degrees of being delighted, pleased, and satisfied. Functionalism does not seem to be able to explain the degrees of strength of a particular attitude type, according to Goldman. Goldman then draws this conclusion: "Since we apparently have introspective access to such positions, self-ascription of these terms invites an introspectivist account (or a quasi-introspective account that makes room for microfeatures of awareness)." (p.24)

Stored or long-term beliefs and desires do not seem to be felt in the same way as occurrent beliefs and desires. Goldman classifies long-term propositional attitudes as 
dispositions, which can be activated into occurrent attitudes. It is in their occurent state that we have our primary understanding of those attitudes.

\section{Attitude contents:}

Attitude contents are also felt, even though we do not necessarily have words for all the feelings associated with attitude contents. Goldman draws an analogy between awareness of mental content and awareness of sentence interpretation. We are aware of only one viable mental content, the other possibilities having been filtered out by our processing system. It is this awareness that counts as the phenomenological experience of attitude contents.

So what is awareness? It seems from Goldman's brief explanation that it is a particular feeling: "The relevant notion of awareness, or consciousness, then, may be that of qualitative or phenomenological character (there being "something it is like") rather than verbal reportability." (p.25) There are some things we feel even though we do not have any words to describe that feeling. Goldman focuses his description of our experience of content on the naive cognizer's understanding of the content. Anything we are not aware of does not count as mental content - it is something else that is part of the processing system, but it is not "content". "Our view of mental content is, I suggest, driven by the cases of which we are aware, although they may be only a minority of the data structures or symbolic structures that occupy the mind."(p.25)

So then, according to Goldman, mental states are not unobservable entities that need to be postulated in order to understand our behaviour and our experiences. Like the theory-theorist, Goldman thinks that mental states exist in a system which links mentalistic concepts such as beliefs and desires to external behaviour and to environmental inputs, but those mental states are known through qualitative experience. A qualitative instance is not a representation of the mental state -- it is the mental state. 
Self knowledge is the state matched to a CR. The child learns to relate her own experiences of states to experiences had by others. During that learning process, mistakes are made which demonstrate a poor understanding of the fact that different people have different experiences. With practice, they begin to distinguish between their experiences and the experiences of others, and come to be able to imagine themselves in the place of the other.

There is, however, a gap between phenomenological experience and an understanding of mental concepts. Goldman tries to connect the two with a story about matching. Qualitatively experienced instances are matched to mental categories or kinds. In his account, "direct access" takes on additional meaning; it no longer is simply experience, but is also understanding of that experience by virtue of being connected to a CR. This is a more sophisticated version than most ST accounts, but it cannot shake the problem of reliance on introspection in our understanding of mental processes. Conscious recognition of mental states still begins the process of understanding.

Goldman's suspicion of functionalism seems to add up to the fact that a relational positioning of mental states is not what experiencing mental states "feels like". Also that the structure that has to support the roles that functionalism assigns to mental states is unimaginable or unimaginably complex (e.g. a huge series of relations, some kind of method of dealing with counterfactuals, etc.). But the functionalist is not required to describe what mental states and the relations between mental states look like. It is fully within the rules for the functionalist to outline a structure which includes black boxes that can be filled in later on or by someone interested in that aspect of mental states. Goldman sometimes seems to equate psychological functionalism with physical functionalism - as the underlying physical (neurological) cause of our qualitative instances -- as though the functionalist view held that psychological functional roles were actual things on which qualia supervenes. Functionalism, rather, is a view about psychological states in which 
those states are understood by how they all fit together. This does not mean that functionalism and phenomenological qualities of mental states are mutually exclusive.

The question that is the interesting one to come out of Goldman's account is the question about where our qualitative experience fits in to the whole FP story. It does fit in somewhere, but I do not think it plays the essential role in self knowledge that Goldman assigns it.

To begin with, even if we did understand our own mental states as qualitative feels, we would still need a functionalist theory to attribute mental states to others. Otherwise how do we "get over" to where they are? Non-functionalist choices are either by inference/analogy or by "imaginative interpretation", both of which are problematic. Whether or not there is an accompanying feeling or whether we imagine a feeling for other people's states along with the attribution is of no consequence. The essential method of attribution is via theory.

In any case, it is more interesting to examine the place of intrinsic qualities in the case of self attribution, since that is what Goldman is referring to and it seems to be the case in which intrinsic qualities of states play a more essential role. It is easier for the friend of qualia to relinquish the central role of qualia in mental state attribution for others than it is for the self. I will show that even in self attribution, qualia do not play an essential role.

A good test of whether we use only qualitative properties to assign mental states to ourselves (whether mental words are about qualitative experiences) is to examine situations in which qualitative properties do not play a central role. I will discuss three such situations: I) those in which we are mistaken in our own mental ascriptions, 2) those in which we make correct ascriptions for ourselves even though the phenomenological quality is missing or in opposition to the mental state attributed, and 3) those in which we are completely unaware of how it is we know what we know, even when pressed. 


\section{Mistaken Attribution}

As has been discussed, there are plenty of documented cases in which we are in error with regards to our own mental states, for example not being able to predict a right-hand bias, or accepting false personality traits given by experimenters. There also is a store of common knowledge about self deception. Witness the statement: "I am NOT upset!! I know I am crying, but I'm just tired, that's all" or, "I don't believe in superstition. I just throw salt over my shoulder when I spill it", or, "I really am quite a modest person". This is not to say that there exists a definite mental state about which we are in error; instead, these sorts of situations betray a discrepancy between verbal report of mental state and behaviour. These are situations in which outward behaviour does not match up with the mental words that are associated with the behaviour of the subject, and this discrepancy is observable to all but the subject who is self-assigning the mental words. Another example is the testimony of someone who sincerely believes in and who says that they believe in affirmative action, but when they are shown (e.g.) examples of their own inequal hiring practices or videos of themselves in which their interviews with blacks and whites are shown to display different body language and tone of voice, they are genuinely surprised about what they actually believe.

What would explain the discrepancy between the mental state assigned according to qualitative feel and outward behaviour? How could the mental states that are normally associated with the outward behaviour be normally associated except by relying on a theory? It could not be that the qualitative feel is the true mental state, while the outward behaviour is random, or does not match up with anything. Yet that is what a nonfunctionalist, purely recognitional account of psychological states would have to claim, since a recognitional account does not have to place an internal state in connection with observable effects like behaviour.

Goldman attempts to explain error in state attribution with an appeal to "partial matching". Since "direct access" implies full and complete knowledge of our own mental 
states, partial matching explains away error in self ascription. As explained, partial matching occurs when the mind jumps ahead to a match between an I and a CR before all the information is in. This leads to incorrect matching. Jumping the gun can be a result of ingrained expectations ("response biases"), for example, "prior expectation of a certain sensation." But are not ingrained expectations evidence of a theory of mind in the TT sense? Where would expectations come from if not from a general theory about what sensation is connected to which environmental inputs? It seems that in a purely recognitional account, there really is no such thing as error, because there has to be some norm that determines what is the correct state and what is the incorrect state to assign. If the mental state just is the instance of a qualitative property, what is the standard for its matching up with a CR? The standard has to be whether it fits in with the apparent causes and effects and other mental states.

This criticism is a different way of putting the cognitive penetrability argument outlined earlier: a theory can be in enror because it is possible for a theory to be wrong. A capability can not be in error. The usual ST response to the cognitive penetrability argument is to claim that the system (the self) does not have all the same input as the target system (the other person). In own-state attribution, however, this response does not make any sense, since there is no other system to be imitated.

\section{Absent or Contradictory Intrinsic Qualities}

A second difficult case for the recognitional account are those situations in which we make mental ascriptions when the phenomenological clue is absent or even contradictory. For example, someone eats an enormous meal and says, "I ate that whole thing and I didn't realize I was even hungry at all", or in a relationship situation: "I wasn't aware that I resented you so much until it came out in my actions", or "I didn't know I was so in love at the time". Contradictory phenomenal qualities are feelings such as attention to unimportant detail in a moment of fear, or tears and an overwhelming feeling of sadness 
in moments of great joy, the urge to laugh in serious situations (or when one feels sad or serious), like at a funeral.

In these cases, we are certainly attributing mental states to ourselves. We attribute states such as hunger, belief, resentment, etc., even though the feelings associated with those states are absent. The feeling that goes with a mental state is not a necessary component in order for us to say or think that we are in that mental state. Again, how could these kinds of attributions be anything but the result of a theory we have about what state goes with what behaviour?

Ignorance of a mental state ("I didn't realize I was feeling that way/was hungry/hurt my foot, etc.") is explained away by Goldman by appeal to focus of attention. If attention is focused away from the sensation referred to, "there may be no attempt to match certain sensations to any category representation. Even an itch or a pain can go unnoticed when attention is riveted on other matters." But again, if the hunger/pain/feeling happens by way of a matching to a $\mathrm{CR}$, how did the sensation occur at all, to be noticed later? Is there unconscious feeling and matching as well as conscious feeling and matching? If so, what has that to do with direct access or phenomenological experiencing? Where does the intrinsic quality of the current mental state come in, and what part does it play? On a recognitional account of state attribution, delayed or absent recognition implies some other method of state attribution.

\section{Automatic Knowledge}

In cases of what I call automatic knowledge, intrinsic qualities are also absent but in a different sort of way. These kinds of cases demonstrate the automaticity of theory, much like Gopnik's illusion of expertise. A chess player who "sees" the forces on the board and an infielder who instantly "sees" where to run to catch the ball both have automatic knowledge. In these cases, it is evident that we are relying on a theory of some kind, whether it be a theory of trajectories, or the rules of chess; but when asked how we do 
any of these skills, we don't have an answer. The outfielder will typically say he doesn't know how he knows where to go to catch the ball, not that he relies on a theory of trajectories. In these cases, subjects are relying on a theory, even though it doesn't feel like they are relying on a theory. That same kind of dependence on a theory applies to mental state attribution even though we are not aware of using any theory.

Can't we take Goldman's point and acknowledge that beliefs and desires are at least grounded in some kind of qualitative feel? Even if our attributions are not essentially phenomenological, neither can they be purely formally structured; for experiencing mental states is part of what makes us human as opposed to some other system that also has functionally defined states.

The functionalist does not call for an eradication of intrinsic qualities. The claim is, rather, that the essential definition and understanding of mental states is functional. This is not equivalent to saying that qualitative states play no part at all in mental state attribution or that they have nothing to do with mental states. They do. However, the presence of qualitative feeling is not necessary for mental state attribution, while functional role is. A way to understand this is to examine the connection between recognition and understanding in a non mental area.

Part of Goldman's critique is that it would be cumbersome to invoke the entire theoretical apparatus every time a mental state is attributed. All the various causal relations to other causal relations is just too hefty a tool to wield regularly. But wouldn't this criticism apply also to those predictions and actions that are agreed to be based on theory? For example, in chemical recognition, a chemist does not necessarily invoke all the chemical connections she knows are attached to a particular substance. The chemist may instantly recognize a brick of gold by its colour, or even by the fact that it is around someone's wedding finger, without having in mind all the chemical connections of the 
substance. The qualities she uses to recognize the gold are not even a necessary part of an essential definition of what gold is. She does not have to run through all the counterfactual definitions and possible chemical reactions related to gold when she recognizes the metal around someone's finger as gold. Instead, she relies on a constant, salient fact about gold in order to call that substance gold.

Of course, the chemist must have had some original kind of notion of gold so that she could later learn all the chemical connections that go along with an understanding of the substance gold. But even though as a young child she understands gold to be that thing around the wedding finger, and even though that was how she always recognized gold and knew (correctly) that whenever she saw a wedding ring that it was gold, that understanding does not constitute a full or an essential understanding of the substance gold. It is an idiosyncratic relation with gold in which she sometimes recognizes a piece of gold by one of its salient features. Is this recognition that is peculiar to the young chemist possibly considered to be a grasp of the concept of gold? It is not. She can not be said to be beginning to grasp the concept until she begins to have a functional definition of the substance. Similarly, we cannot be said to have grasped the concept of a mental state until we understand it in its functional place. Our grasp of the concept is incomplete until we place it in a functional role. It is not the primary element in understanding of mental state concepts. A theory of other minds places mental states into this functional place. It is in its use in a theory that a mental state has its essential meaning.

An introspective account of mental states is by no means inconsequential, however. We regularly identify mental states by their intrinsic qualities. If our theory is implicit or ingrained after so much practice that we no longer notice it, intrinsic qualities of mental states can seem to be the only way that we identify mental states. And phenomenological qualities may well be a part of a functional definition. Phenomenal qualities may be connected to mental states in a functional relation (one of the causal relations of a mental state is its connection to a feeling). Or, as outlined by Carruthers, 
being in a mental state automatically produces a feeling that goes along with that state. Or a feeling develops after the theory of that state has been practiced for awhile.

All of these are interesting and possible. No-one is saying that there are no feelings attached to mental states or even that we do no regularly identify our own mental states by phenomenological qualities. However, the intrinsic qualities that are associated with mental states are not necessary for our having those mental states or for our attributing those mental states to ourselves.

So even if a cognitive process is always accompanied by vivid imagery, that is no reason at all to suppose that the process exploits off-line simulation. From this we draw the obvious conclusion. The fact that prediction and interpretation sometimes involve imagining oneself in the other person's shoes is less than no reason at all to suppose that off-line simulation is involved. (Stich and Nichols 1992, p.69)

The fact that intrinsic qualities are not necessary for mental state attribution is evident when we attribute mental states to ourselves and others in the absence of any phenomenological quality. Also we are regularly "in" a mental state without the attached feeling. Introspection to intrinsic quality is just one clue that helps to identify the internal mental state. What is necessary and essential to the understanding of any particular mental state is its functional role. We need to have some kind of knowledge of the functional role of a mental state, otherwise we could not attribute mental states to others. And we must use that knowledge on ourselves, otherwise we could not be in error about our own mental states. 


\section{Conclusion}

Individual experiments from developmental psychology seem to able to be explained to an acceptable degree both on the simulation theory and on the theory theory. However, once the debate is set up as a functionalist vs. a non-functionalist understanding of mental states, the story of mental state attribution as a whole becomes highly improbable on a non-functionalist account. There are particular areas of mental state attribution that can be accounted for on a non-functionalist account (for example, some kind of non essential recognition of the mental states one is in). However, the story as a whole, which includes attribution of mental states to others, attribution of mental states to self, and in particular, instances of self attribution without the corresponding phenomenological qualities can only be explained on a functionalist account.

Error in attribution of one's own mental states is an area in folk psychology full of potential ammunition for the theory theorist. As it stands now, there is not much in the way of a systematic evaluation of the phenomenon of discrepancy of mental state attribution with behaviour. Nisbett and Ross (1980) published a number of tantalizing experiments documenting cases of error in self attribution. More needs to be done in this area, especially now that theories of theories of mind have developed to an advanced state. Empirical research in this area would compliment the research being done in developmental psychology. Much can be learned from the point in our lives when we acquire a theory of mind, but also from our adult lives when we use this theory of mind regularly. When does it not work? Why are some people better at using it than others? Why do we often have difficulty applying it to ourselves? And how often does it not work? The answers to these questions could further our understanding of the attribution of mental states. 


\section{Bibliography}

Boucher, J. (1996). What could possibly explain autism? In P. Carruthers and P. Smith (eds.), Theories of Theories of Mind. Cambridge: Cambridge U. Press 223-41

Carruthers, P. and Smith, P. (eds.) (1996), Theories of Theories of Mind. Cambridge: Cambridge U. Press.

Churchland, P.M. (1981). Eliminative materialism and propositional attitudes. In S. Christensen and D. Turner (eds.) Folk psychology and the Philosophy of Mind. Hillsdale, NJ: Lawrence Erlbaum and assoc.

(1989). Folk psychology and the explanation of human behavior. In J. Greenwood (ed.) The Future of Folk Psychology. Cambridge: Cambridge U. Press.

Davies, M. (1993). The mental simulation debate. In C. Peacocke (ed.), Objectivity, Simulation, and the Unity of Consciousness. Oxford: Oxford U. Press.

Davies, M. and Stone, T. (eds.), (1995a). Folk Psychology. Oxford: Basil Blackwell. (1995b). Mental Simulation. Oxford: Basil Blackwell.

Dennett, D. (1982). Making sense of oursleves. In J. Biro and R Shahan (eds.), Mind, Brain and Function. Brighton: Harvester Press.

Fodor, J. (1996) The mind-body problem. In S. Cahn, R. Kitcher, G. Sher, P. Markie (eds.), Reason at Work: Introductory Readings in Philosophy. 3rd ed. NY:

Harcourt Brace College Publishers.

Goldman, A. (1989). Interpretation psychologized. Mind and Language, 4, 161-85.

(1993). The psychology of folk psychology. Behavioral and Brain Sciences, 16, 15-28.

Gopnik, A. (1993). How we know our own minds: The illusion of first person knowledge of intentionality. Behavioral and Brain Sciences, 16, 1-14.

Gopnik, A. and Astington, J. W. (1988). Children's understanding of representational change and its relation to the understanding of false belief and the appearancereality distinction. Child Development, 59, 1366-71

Gopnik, A. and Wellman, H. (1992). Why the child's theory of mind really is a theory. Mind and Language, 7:1-2, 145-71.

Gordon, R. M. (1986). Folk psychology as simulation. Mind and Language, 1, 158-71. 
(1992a). The simulation theory: Objections and misconceptions. Mind and Language, 7 [1-34

(1992b). Reply to Stich and Nichols. Mind and Language, 7, 85-97.

(1992c). Reply to Perner and Howes. Mind and Language, 7, 98-103.

(1995). Simulation without introspection or inference from me to you. In T. Stone and M. Davies (eds.).Mental Simulation. Oxford: Blackwell

(1996). "Radical" simulation. In P. Carruthers and P. Smith (eds.). Theories of Theories of Mind. Cambridge: Cambridge U. Press.

Harris, P. L. (1991). The work of the imagination. In A. Whiten (ed.), Nutural Theories of Mind: Evolution, Development and Simulation of Everyday Mindreading.

Oxford: Blackwell

(1992). From simulation to folk psychology: The case for development. Mind and Language, 7, 120-44.

Heal, J. (1986). Replication and functionalism. In J. Butterfield (ed.), Language, Mind, and Logic (pp. 135-50). Cambridge, Cambridge U. Press.

(1996). Simulation and cognitive penetrability. Mind and Language, 1 1, 44-67.

Jackson, F. (1982). Epiphenomenal qualia. Philosophical Quarterly, 32, 127-36.

Kahneman, D., and Tversky, A. (1982). The simulation heurisitc. In D. Kahneman, P. Slovic, and A. Tversky (eds.), Judgement Under Uncertainty. Cambridge: Cambridge U. Press.

Moore, C., Pure, K., and Furrow, D. (1990). Children's understanding of the modal expressions of speaker certainty and uncertainty and its relation to the development of a representational theory of mind. Child Development, 61,722-30.

Nisbett, R. and Ross, L. (1980). Human Inference. Englewood Cliffs, NJ: PrenticeHall.

Permer, J. and Howes, D. (1992) "He thinks he knows"; and more developmental evidence against the simulation (role-taking) theory. Mind and language, 7, 72-86.

Pratt, C., and Bryant, P.E. (1990). Young children understand that looking leads to knowing (so long as they are looking into a single barrel). Child Development, 61 , 973-82.

Russell, B. (1948). The argument from analogy from other minds. In J. Perry and M. Bratman (eds.), Introduction to Philosophy. Classical and Contemporary Readings. 2nd ed. Oxford: Oxford U. Press 
Stich, S. and Nichols, S. (1992). Folk psychology: simulation or tacit theory? Mind and Language, 7, 35-71.

(1995). Second thoughts on simulation. In T. Stone and M. Davies, (eds.), Mental Simulation. Oxford: Blackwell.

Wimmer, H., Hogrefe, J., and Sodian, b. (1988) A second state in children's conception of mental life: Understanding informational access as origins of knowledge and belief. In J. Astington, P. Harris and D. Olsen (eds.), Developing Theories of Mind. Cambridge:Cambridge U. Press.

Wimmer, H. and Perner, J. (1983). Beliefs about beliefs: Representation and constraining function of wrong beliefs in young children's understanding of deception. Cognition, 13, 103-28. 